تأثير الخدمات اللوجستية في دول مجلس التعاون الخليجى على التجارة البينية لدول مجلس التعاون

\author{
بثار نبيل الملا

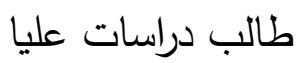

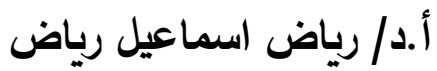 \\ أستاذ الإقتصاد الزراعي، جامعة العري اصئ رياص

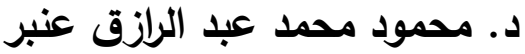 \\ مدرس الاقتصاد، جامعة أسوان
}


تزايدت أهمية الخدمات اللوجستية كثيراً في السنوات الأخيرة، بفعل اشتداد المنافسة وتزايد الطلب

على خدمات أسرع وأفضل لكي تلبي احتياجات الأسواق العالمية، فالبلدان المتقدمة مثل النامية تستثر كثيراً في تحسين الخدمات اللوجستية، والمنطقة العربية لاتختلف عنها. وعلى مر السنين قامت عدة دول عربية بتحسين أدائها اللوجستي وفي مجالات أخرى ذات صله، مثل الربط بالثبكات البحرية العالمية.، وسجلت دول الخليج العربي حضوراً لافتاً في مؤشر دولي للأسواق الناشئة لقياس القدرة التنافسية في الخدمات اللوجستية، إذ جاءت السعودية والإمارات بين أعلى عشر دول في العالم. واحتلت دول الخليج مراكز متقدمة في التصنيف؛ حيث حصدت الإمارات المركز الثالث، والسعودية الساد،، وعمان في المرتبة الـ ا، والبحرين في اله 1، والكويت حلت في المرتبة الـ9 (، بينما من دول جنوب شرقي آسيا؛ احتلت إندونيسيا المركز الرابع، وماليزيا الخامس، وتايلاند التاسع، وفيتنام الحادي عشر نتيجة لأدائها القوي.، وبهذه النتائج، تكون دول الخليج العربي تفوقت على معظم الأسواق الناشئة الأخرى في الإصدار الحادي عشر من مؤشر 》أجيليتيه اللوجستي للأسواق الناشئة، الذي يقيس القدرة التتافسية لهذه الأسواق بناء على قوة الخدمات اللوجستية وأساسيات مزاولة الأعمال . وقد حدث تحسن طفيف في نمو اقتصاد مجلس التعاون الخليجي في عامي 2018 م و 2019 م نتيجة التزام دول مجلس التعاون بخفض الإنتاج ضمن اتفاق منظمة أوبك والمنتجين المستقلين لدعم أسعار النفط في الأسواق العالمية، وعليه سيعتمد نمو الاقتصاد في مجلس التعاون بشكل أساسي على القطاعات غير النفطية خلال الفترة القادمة.، وفي المقابل سيثكل إرتفاع أسعار الفائدة وزيادة تكاليف 
الاقتراض بالنسبة للمسهلكين والثركات، مع إنخفاض مستويات الإستهلاك والاستثمار والنشاط التجاري في إضافة المزيد من الضغوط على الأداء الاقتصادي . وتوجد صلة جوهرية بين الأداء اللوجستي لدولة ما وإنتاجيتها وقدرتها عل المنافسة ونموها الاقتصادي المستدام على الصعيدين الوطني والإقليمي، فمهوم اللوجستيات يرتبط بعناصر التقدم الاقتصادي من خلال قدرتها على تقليل تكاليف الإنتاج عن طريق تخفيض تكاليف النقل والتخزين والتوزيع، وتحسين المنتج المقدم للعميل، وهذا يؤدي إلى تنافسية الصادرات وتخفيض أسعار الواردات؛ ومن ثم تحقيق الهدف الأسمى من إدارة اللوجستيات وهو إرضاء العميل' . الكلمات الدالة : الخدمات اللوجستية ، مجلس التعاون الخليجى ، التجارة البينية مشكلة الاراسة: هل هناك أثر للخدمات اللوجستية فى دول مجلس التعاون الخليجى على التجارة الخارجية فى

-ما مدى تأثير الخدمات اللوجستية فى دول مجلس التعاون الخليجى على التجارة البينية لدول مجلس التعاون؟ وسوف نلقي الضوء في هذا الجزء من الدراسة على أثر تطور الخدمات اللوجستية بدول مجلس التعاون الخليجي على التجارة البينة لدول مجلس التعاون من خلال دراسة مدى تطور التجارة الخارجية الدولية، التجارة البينة لدول مجلس التعاون الخليجي

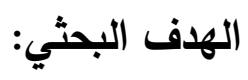

1 ا مني عبد العال سيد، إستكثاف فرص النمو من خلال الخدمات اللوجستية بالتطبيق على الموانئ المصرية، سلسلة

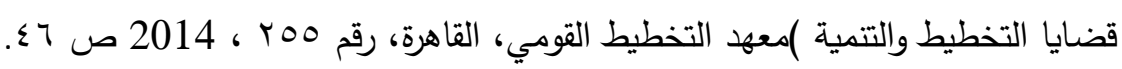


استهدف البحث التعرف على أثر الخدمات اللوجستية في دول مجلس التعاون الخليجى على

$$
\text { التجارة البينية لدول مجلس التعاون. }
$$

اعتمد البحث على اسلوب الاقتصاد الوصفي والقياسي من خلال استخدام تحليل الانحدار

البسيط وتقدير معدلات النمو.، كما اعتمد البحث للحصوال على البيانات على المنظمة العالمية للتجارة ،

البنك الدولي، وبعض الدراسات والكتب ذات الصلة بموضوع البحث بالإضافة شبكة المعلومات الدولية.

\section{النتائج البحثية}

أولاً: دراسة مؤشرات التجارة الخارجية العالمية لدول مجلس التعاون الخليجي خلال الفترة من $:(r+19-r+1)$

باستعراض البيانات الواردة بجدول رقم (1) تبين أن إجمالي قيمة صادرات دول مجلس التعاون الخليجي

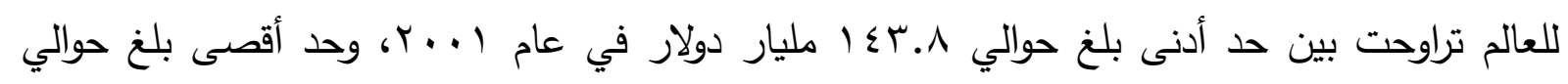

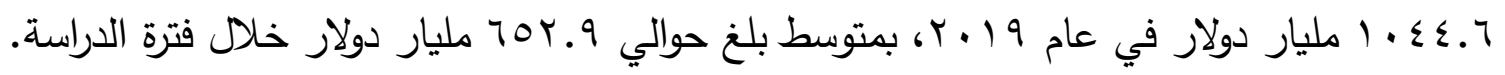
وبتقدير معادلة الإتجاه الزمني العام لإجمالي قيمة صادرات دول مجلس التعاون الخليجي خلا فترة الدراسة تبين أنه ارتفع بمعدل نمو سنوي معنوي إحصائياً عند المستوى الإحتمالي ا... ٪ بلغ نحو ؟.9\% خلال نفس الفترة وقد بلغت قيمة معامل التحديد المعدل حوالي 9.ب٪\% مما يدل على أن النموذج يفسر حوالي ء؟ ٪ من التغيرات التي تحدث لإجمالي قيمة صادرات دول مجلس التعاون كما يتضح من المعادلة التالية:

$$
\begin{gathered}
\operatorname{Ln} \hat{Y}_{\mathbf{i}}=5.413+0.092 \mathrm{~T}_{\mathbf{i}} \\
(29.75)^{* *} \\
\mathbf{F}=(\mathbf{3 2 . 7 4})^{* *} \\
\mathbf{R}^{-2}=\mathbf{0 . 6 3 9}
\end{gathered}
$$


كما تبين أن إجمالي قيمة واردات دول مجلس التعاون الخليجي تراوحت بين حد أدنى بلغ حوالي

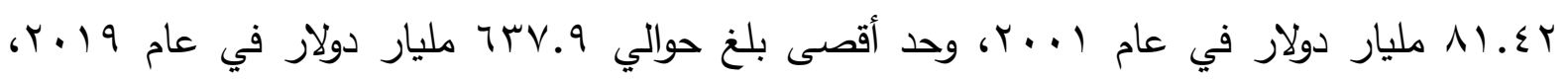
بمتوسط بلغ حوالي r.4.T مليار دولار خلال فترة الدراسة. وبتقدير معادلة الإتجاه الزمني العام لإجمالي قيمة واردات دول مجلس التعاون الخليجي خلال فترة الدراسة تبين أنه ارتفع بمعدل نمو سنوي معنوي إحصائياً عند المستوى الإحتمالي ا ... ٪ بلغ نحو У.. 1\% خلال نفس الفترة وقد بلغت قيمة معامل التحديد المعدل حوالي ؟.؟^٪ مما يدل على أن النموذج يفسر حوالي ؟^٪ من التغيرات التي تحدث لإجمالي قيمة واردات دول مجلس التعاون كما يتضح من المعادلة التالية:

$$
\begin{aligned}
& \operatorname{Ln} \hat{\mathbf{Y}}_{\mathrm{i}}=4.669+0.107 \mathrm{~T}_{\mathrm{i}} \\
& (37.82)^{* *} \quad(9.91)^{* * *} \\
& \mathbf{F}=(\mathbf{9 8 . 1 8})^{* *} \quad \mathrm{R}^{-2}=0.844
\end{aligned}
$$

\begin{tabular}{|c|c|c|c|c|c|}
\hline نسبة تغطية الصنادرات & الميزان التجاري & إجمالي التبادل & واردات & صادرات & السنوات \\
\hline 176.66 & 62.42 & 128.43 & 81.42 & 143.84 & 2001 \\
\hline 169.72 & 67.77 & 159.56 & 97.19 & 164.96 & 2002 \\
\hline 177.30 & 92.76 & 200.41 & 119.99 & 212.75 & 2003 \\
\hline 188.32 & 133.39 & 264.95 & 151.03 & 284.42 & 2004 \\
\hline 215.50 & 208.80 & 332.84 & 180.77 & 389.57 & 2005 \\
\hline 217.42 & 257.41 & 417.35 & 219.22 & 476.63 & 2006 \\
\hline 185.46 & 245.41 & 499.03 & 287.15 & 532.56 & 2007 \\
\hline 227.50 & 486.85 & 825.25 & 381.84 & 868.69 & 2008 \\
\hline 210.94 & 367.65 & 746.14 & 331.38 & 699.03 & 2009 \\
\hline 210.55 & 411.61 & 802.07 & 372.33 & 783.94 & 2010 \\
\hline 222.48 & 523.77 & 886.96 & 427.65 & 951.42 & 2011 \\
\hline 196.60 & 490.71 & 968.06 & 508.00 & 998.70 & 2012 \\
\hline 179.01 & 448.17 & 1044.30 & 567.25 & 1015.42 & 2013 \\
\hline 168.19 & 394.27 & 1040.44 & 578.18 & 972.45 & 2014 \\
\hline 124.93 & 141.30 & 891.75 & 566.90 & 708.20 & 2015 \\
\hline 119.49 & 91.46 & 721.33 & 469.27 & 560.73 & 2016 \\
\hline 138.16 & 193.74 & 862.43 & 507.76 & 701.50 & 2017 \\
\hline 175.35 & 384.75 & 976.30 & 510.65 & 895.40 & 2018 \\
\hline 163.75 & 406.65 & 1286.33 & 637.91 & 1044.56 & 2019 \\
\hline
\end{tabular}

جدول رقم (1): مؤشرات التجارة الخارجية لمجلس التعاون الخليجي خلال الفترة ( (. ץ-9 1 + ؟): القيمة بالمليار دولار 
مجلة البحوث والداسات الإفريقية ودول حوض النيل - جامعة أسون - المجلد (r) - العدد (r) - يناير ( r +r م)

\begin{tabular}{c|c|c|c|c|c}
\hline \hline 179.69 & 284.68 & 687.05 & 368.20 & 652.88 & متوسط \\
\hline \hline
\end{tabular}

المصدر: Trade statistics for international business development Trade map

واتضح أن إجمالي قيمة التبادل التجاري لدول مجلس التعاون الخليجي تراوحت بين حد أدنى بلغ

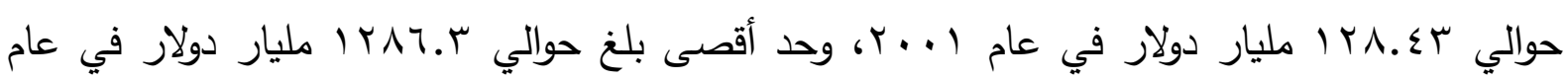
I 9 ـ T، بمتوسط بلغ حوالي TAV مليار دولار خلال فترة الدراسة. وبتقدير معادلة الإتجاه الزمني العام لإجمالي قيمة التبادل التجاري لدول مجلس التعاون الخليجي خلال فترة الدراسة تبين أنه ارتفع بمعدل نمو سنوي معنوي إحصائياً عند المستوى الإحتمالي ا ... بلغ نحو 11\% خلال نفس الفترة وقد بلغت قيمة معامل التحديد المعدل حوالي 9. 9 \% مما يدل على أن النموذج يفسر حوالي VV\% من التغيرات التي تحدث لإجمالي قيمة التبادل التجاري لدول مجلس التعاون كما يتضح من المعادلة التالية: - n

$$
\begin{gathered}
\operatorname{Ln} \hat{Y}_{\mathrm{i}}=\underset{5.248+0.110 \mathrm{~T}_{\mathrm{i}}}{(32.62) * *} \quad \begin{array}{c}
(7.80)^{* * *} \\
\mathbf{R}^{-2}=\mathbf{0 . 7 6 9}
\end{array} \\
\mathbf{F}=(60.85)^{* * *}
\end{gathered}
$$

كما اتضح أن الميزان التجاري لدول مجلس التعاون الخليجي تراوحت بين حد أدنى بلغ حوالي

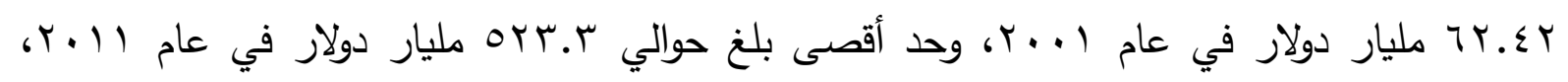

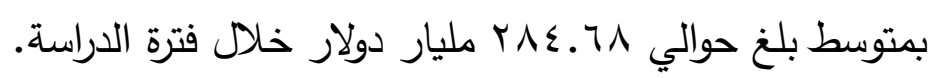
وبتقدير معادلة الإتجاه الزمني العام للميزان التجاري لدول مجلس التعاون الخليجي خلال فترة الدراسة تبين أنه ارتفع بمعدل نمو سنوي معنوي إحصائياً عند المستوى الإحتمالي ه... ٪ بلغ نحو

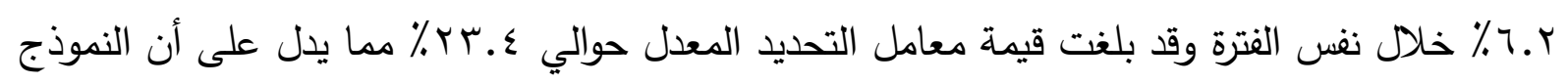
يفسر حوالي بr ٪ من التغيرات التي تحدث للميزان التجاري لدول مجلس التعاون كما يتضح من المعادلة التالية:

$$
\operatorname{Ln} \hat{Y}_{i}=4.824+0.062 T_{i}
$$


مجلة البحوث والداسات الإفريقية ودول حوض النيل - جامعة أسون - المجلد (ץ) - العد (ץ) - يناير ( Y r م م)

$$
\mathbf{F}=(\mathbf{5 . 4 5})^{(15.82) * *} \mathbf{R}^{-2}=0.243
$$

كما تثير بيانات الجدول أن نسبة تغطية الصادرات للواردات لدول مجلس التعاون الخليجي

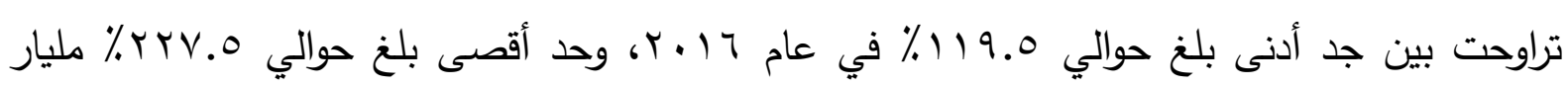
دولار في عام A . . Y، بمتوسط هندسي بلغ حوالي V.V. مليار دولار خلال فترة الدراسة. وبتقدير معادلة الإتجاه الزمني العام لنسبة تغطية الصادرات للواردات لدول مجلس التعاون الخليجي خلال فترة الدراسة تبين أنها انخفضت بمعدل انخفاض سنوي معنوي إحصائياً عند المستوى

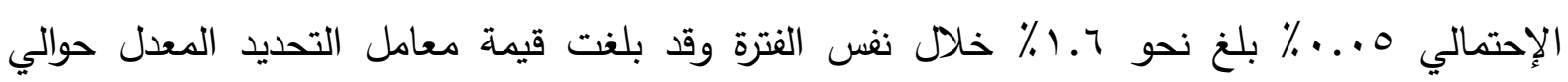

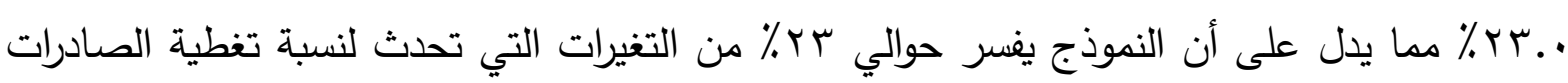
للواردات لدول مجلس التعاون كما يتضح من المعادلة التالية:

$$
\begin{aligned}
& \operatorname{Ln} \hat{Y}_{i}=5.349-0.016 T_{i} \\
& \mathbf{F}=(5.08)^{*}(66.96)^{* *} \mathbf{R}^{-2}=0.230
\end{aligned}
$$

مما سبق يتبين أن الميزان التجاري لدول مجلس التعاون الخليجي مجتمعة يحقق فائض خلال فترة الدراسة على الرغم من انخفاض نسبة تغطية الصادرات للواردات لدول مجلس التعاون، وقد يفسر هذا نتيجة نمو صادرات دول مجلس التعاون بمعدل أقل من معدل نمو واردت دول مجلس التعاون خلال نفس الفترة. ا- تطور التجارة الخارجية لدولة السعودية وأهميتها النسبية لدول مجلس التعاون الخليجي خلال

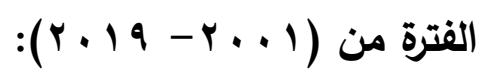
باستعراض البيانات الواردة بجدول رقم (r) تبين أن إجمالي قيمة صادرات السعودية تراوحت بين

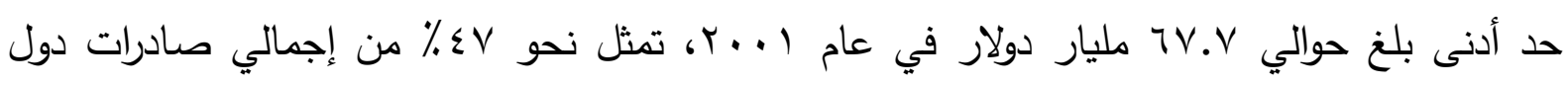

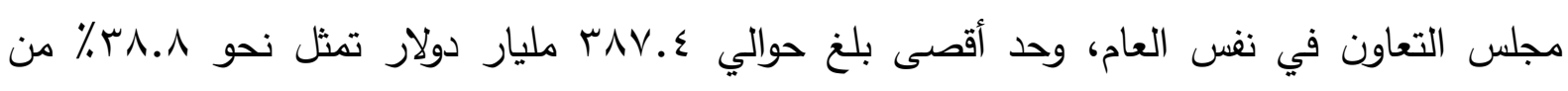




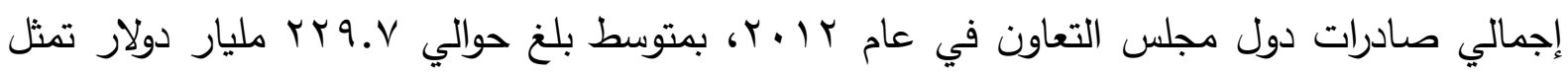
نحو 9 . 1 \% من متوسط إجمالي صادرات دول مجلس التعاون خلال فترة الدراسة. وبتقدير معادلة الإتجاه الزمني العام لإجمالي قيمة صادرات السعودية خلال فترة الدراسة تبين أنه ارتفع بمعدل نمو سنوي معنوي إحصائياً عند المستوى الإحتمالي ا...٪ بلغ نحو ؛.؟٪ خلال نفس

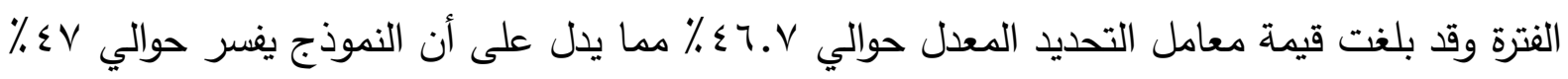
من التغيرات التي تحدث لإجمالي قيمة صادرات السعودية كما يتضح من المعادلة التالية:

$$
\begin{aligned}
& \operatorname{Ln} \hat{Y}_{i}=4.68+0.064 T_{i} \\
& \left.\mathbf{F}=(14.92)^{* * * 76}\right)^{* *} \begin{array}{r}
(3.86)^{* * *} \\
\mathbf{R}^{-2}=\mathbf{0 . 4 6 7}
\end{array}
\end{aligned}
$$

\begin{tabular}{|c|c|c|c|c|c|}
\hline نسبة تلغطية الصنادرات & التجاري & إجمالي التبادل & واردات & صادرات & السنو ات \\
\hline 232.1 & 38.5 & 96.8 & 29.2 & 67.7 & 2001 \\
\hline 236.7 & 41.7 & 102.6 & 30.5 & 72.1 & 2002 \\
\hline 234.4 & 53.2 & 132.3 & 39.6 & 92.8 & 2003 \\
\hline 279.3 & 80.6 & 170.5 & 44.9 & 125.6 & 2004 \\
\hline 315.0 & 123.0 & 237.5 & 57.2 & 180.3 & 2005 \\
\hline 311.5 & 143.1 & 278.5 & 67.7 & 210.8 & 2006 \\
\hline 265.2 & 145.0 & 320.7 & 87.8 & 232.9 & 2007 \\
\hline 278.8 & 200.7 & 425.3 & 112.3 & 313.0 & 2008 \\
\hline 207.5 & 99.4 & 284.3 & 92.5 & 191.8 & 2009 \\
\hline 241.8 & 147.0 & 354.2 & 103.6 & 250.6 & 2010 \\
\hline 284.6 & 236.2 & 492.1 & 128.0 & 364.1 & 2011 \\
\hline 256.1 & 236.1 & 538.6 & 151.3 & 387.4 & 2012 \\
\hline 230.3 & 212.3 & 538.4 & 163.0 & 375.4 & 2013 \\
\hline 203.3 & 173.7 & 510.2 & 168.2 & 341.9 & 2014 \\
\hline 125.5 & 43.4 & 383.3 & 170.0 & 213.4 & 2015 \\
\hline 137.8 & 49.1 & 308.7 & 129.8 & 178.9 & 2016 \\
\hline 173.6 & 93.3 & 346.8 & 126.8 & 220.1 & 2017 \\
\hline 217.8 & 159.3 & 429.7 & 135.2 & 294.5 & 2018 \\
\hline 174.5 & 107.5 & 396.1 & 144.3 & 251.8 & 2019 \\
\hline 225.4 & 125.43 & 334.04 & 104.3 & 229.73 & متوسط \\
\hline
\end{tabular}

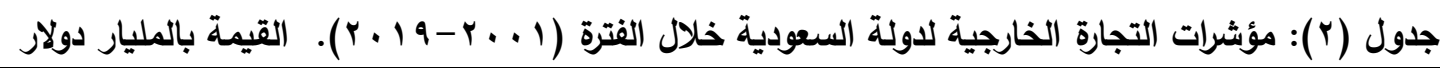

المصدر: Trade statistics for international business development Trade map 
كما تبين أن إجمالي قيمة واردات السعودية تراوحت بين حد أدنى بلغ حوالي r.q مليار دولار تمثل نحو ^.0ץ\% من إجمالي واردات دول مجلس التعاون في عام I....، وحد أقصى بلغ حوالي

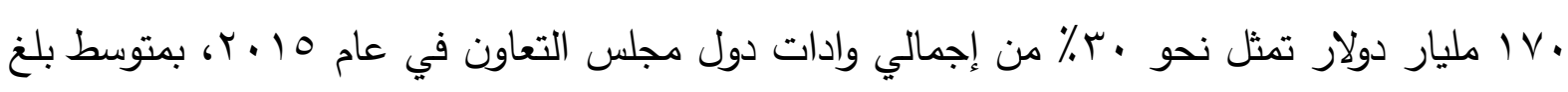

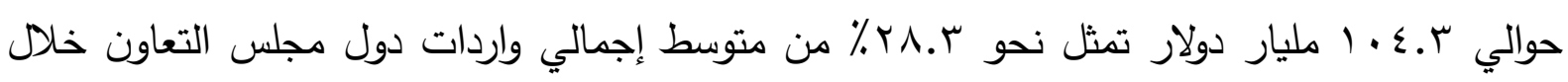
فترة الدراسة. وبتقدير معادلة الإتجاه الزمني العام لإجمالي قيمة واردات السعودية خلال فترة الدراسة تبين أنه ارتفع بمعدل نمو سنوي معنوي إحصائياً عند المستوى الإحتمالي ا ...٪ بلغ نحو r.9٪ خلال نفس

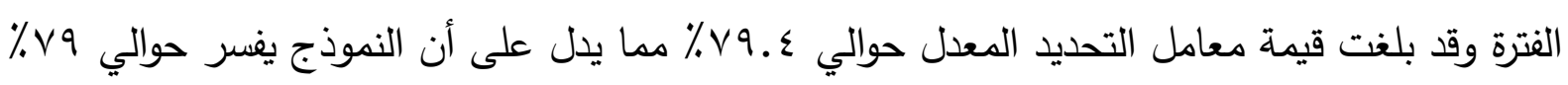
من التغيرات التي تحدث لإجمالي قيمة واردات السعودية كما يتضح من المعادلة التالية:

$$
\begin{gathered}
\operatorname{Ln} \hat{Y}_{\mathrm{i}}=3.59+0.092 \mathrm{~T}_{\mathrm{i}} \\
\begin{array}{cc}
(27.54)^{* * *} & (8.09)^{* * *} \\
\mathrm{~F}=(65.41)^{* * *} & \mathbf{R}^{-2}=0.794
\end{array}
\end{gathered}
$$

واتضح أن إجمالي قيمة التبادل التجاري لدولة السعودية تراوحت بين حد أدنى بلغ حوالي ^.؟ج

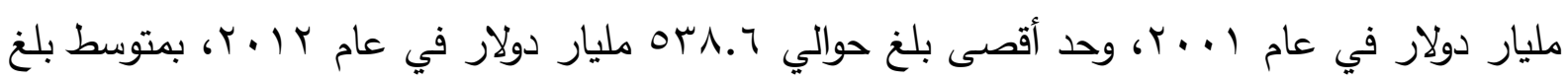
حوالي ع זr مليار دولار خلال فترة الدراسة. وبتقدير معادلة الإتجاه الزمني العام لإجمالي قيمة التبادل التجاري لدولة السعودية عالمياً خلال فترة الدراسة تبين أنه ارتفع بمعدل نمو سنوي معنوي إحصائياً عند المستوى الإحتمالي ا ... ٪ بلغ نحو r. خ. خلال نفس الفترة وقد بلغت قيمة معامل التحديد المعدل حوالي ع. \&\% مما يدل على أن النموذج يفسر حوالي Vه\% من التغيرات التي تحدث لإجمالي قيمة التبادل التجاري لدولة السعودية مع العالم كما يتضح من المعادلة التالية:

$$
\begin{gathered}
\operatorname{Ln} \hat{Y}_{\mathrm{i}}=\begin{array}{c}
4.96+0.073 \mathrm{~T}_{\mathrm{i}} \\
(29.82)^{* * *}
\end{array} \\
\mathbf{F}=(\mathbf{2 5 . 0 3})^{* * *} \\
\mathrm{R}^{-2}=0.574
\end{gathered}
$$


كما اتضح أن الميزان التجاري لدولة السعودية تراوحت بين حد أدنى بلغ حوالي م.ـ مليار

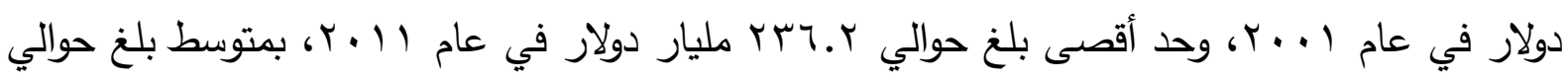

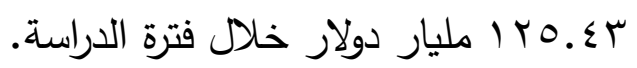

وبتقدير معادلة الإتجاه الزمني العام للميزان التجاري للسعودية تبين عدم دعنوية هذا المتغير. كما تثير بيانات الجدول أن نسبة تغطية الصادرات للواردات للسعودية تراوحت بين حد أدنى بلغ

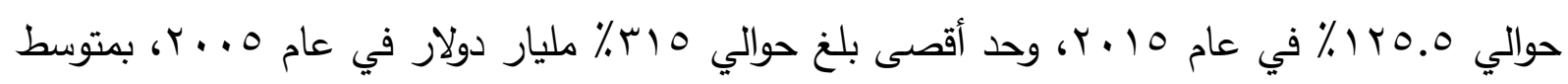

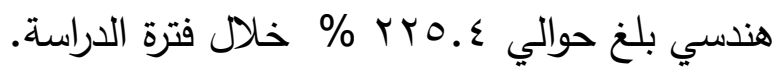
وبتقدير معادلة الإتجاه الزمني العام لنسبة تغطية الصادرات للواردات للسعودية خلال فترة الدراسة تبين أنها انخفضت بمعدل انخفاض سنوي معنوي إحصائياً عند المستوى الإحتمالي ا... ٪ بلغ نحو ^.r\% خلال نفس الفترة وقد بلغت قيمة معامل التحديد المعدل حوالي r.بr\% مما يدل على أن النموذج يفسر حوالي بr\% من التغيرات التي تحدث لنسبة تغطية الصادرات للواردات للسعودية كما يتضح من المعادلة التالية:

$$
\begin{aligned}
& \operatorname{Ln} \hat{Y}_{i}=5.702-0.028 T_{i} \\
& (\mathbf{5 9 . 0 7 )} * * \quad(-3.35) * * \\
& \mathbf{F}=(11.21)^{*} \quad R^{-2}=0.362
\end{aligned}
$$

مما سبق يتبين أن الميزان التجاري للسعودية يحقق فائض خلال فترة الدراسة على الرغم من انخفاض نسبة تغطية الصادرات للواردات لدول مجلس التعاون نظراً لزيادة صادراتها بمعدل نمو أقل من معدل نمو وارداتها خلال نفس الفترة. ץ- تطور التجارة الخارجية لدولة الإمارات وأهميتها النسبية لدول مجلس التعاون الخليجي خلال الفترة من (1 + 
باستعراض البيانات الواردة بجدول رقم (r) تبين أن إجمالي قيمة صادرات الإمارات تراوحت بين حد أدنى بلغ حوالي V.r. مليار دولار تمثل نحو Y.Y. من إجمالي صادرات دول مجلس التعاون في

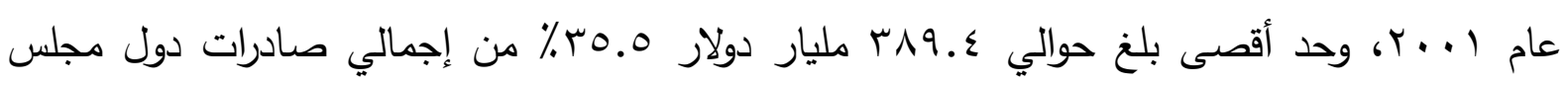

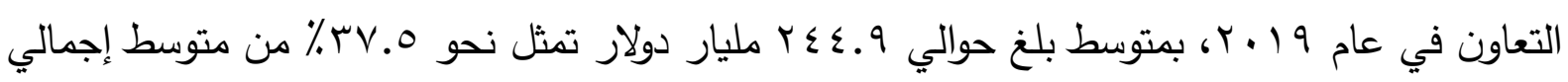
صادرات دول مجلس التعاون خلال فترة الدراسة. وبتقدير معادلة الإتجاه الزمني العام لإجمالي قيمة صادرات دولة الإمارات خلال فترة الدراسة

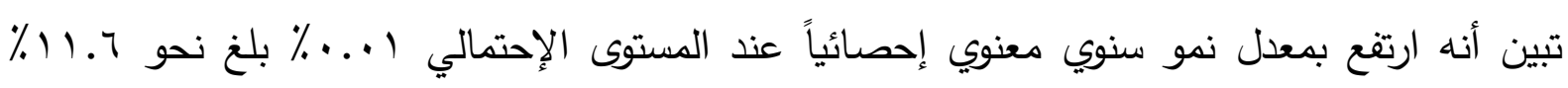
خلال نفس الفترة وقد بلغت قيمة معامل التحديد المعدل حوالي ^. . \٪ مما يدل على أن النموذج يفسر حوالي ال\\% من التغيرات التي تحدث لإجمالي قيمة صادرات الإمارات كما يتضح من المعادلة التالية:

$$
\begin{gathered}
\operatorname{Ln} \hat{Y}_{\mathrm{i}}=\underset{4.134+0.116 \mathrm{~T}_{\mathrm{i}}}{(20.94) * *}(\mathbf{6 . 6 9}) * * \\
\mathrm{~F}=\left(\mathbf{4 4 . 7 4 ) * *} \quad \mathbf{R}^{-2}=0.708\right.
\end{gathered}
$$

كما تبين أن إجمالي قيمة واردات الإمارات تراوحت بين حد أدنى بلغ حوالي ه. ـ مليار دولار

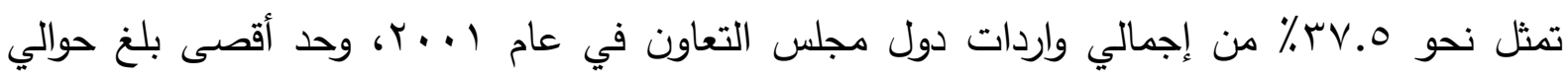

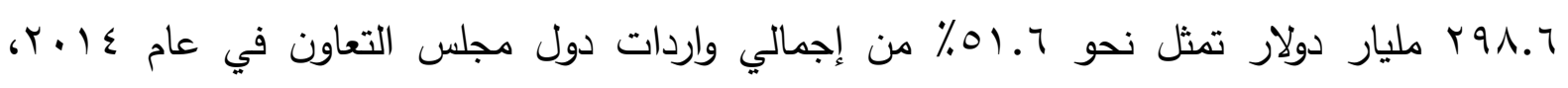

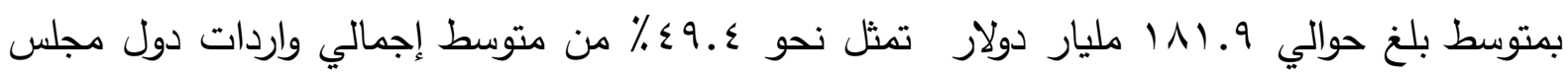
التعاون خلال فترة الدراسة. وبتقدير معادلة الإتجاه الزمني العام لإجمالي قيمة واردات الإمارات خلال فترة الدراسة تبين أنه ارتفع بمعل نمو سنوي معنوي إحصائياً عند المستوى الإحتمالي ا...٪ بلغ نحو 9.11 ٪ خلال نفس الفترة وقد بلغت قيمة معامل التحديد المعدل حوالي ^.ب^^\% مما يدل على أن النموذج يفسر حوالي ع^٪ من التغيرات التي تحدث لإجمالي قيمة واردات الإمارات كما يتضح من الدعادلة التالية:

$$
\operatorname{Ln} \hat{Y}_{i}=3.810+0.119 T_{i}
$$




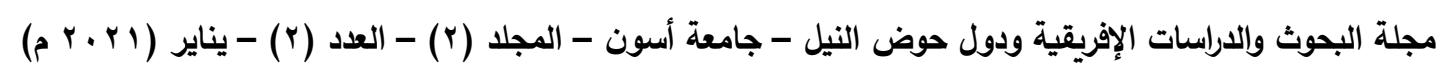

$\left.\mathbf{F}=(\mathbf{9 3 . 8 4})^{* * * 15}\right)^{* *} \underset{\mathbf{R}^{-2}=\mathbf{0 . 8 3 8}}{(\mathbf{9} .69}$

واتضح أن إجمالي قيمة التبادل التجاري للإمارات تراوحت بين حد أدنى بلغ حوالي r.rاج مليار

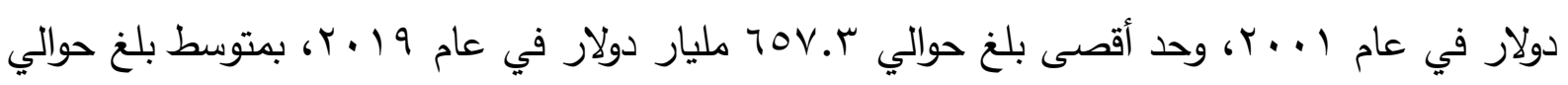

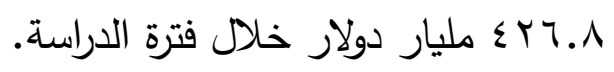
وبتقدير معادلة الإتجاه الزمني العام لإجمالي قيمة التبادل التجاري للإمارات خلال فترة الدراسة

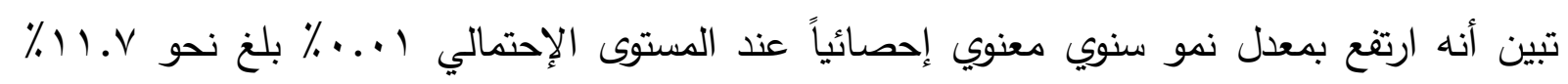
خلا نفس الفترة وقد بلغت قيمة معامل التحديد المعدل حوالي ؟.YV\% مما يدل على أن النموذج يفسر حوالي VV\% من التغيرات التي تحدث لإجمالي قيمة التبادل التجاري للإمارات كما يتضح من المعادلة التالية:

$$
\begin{aligned}
& \operatorname{Ln} \hat{\mathbf{Y}}_{\mathrm{i}}=4.684+0.117 \mathrm{~T}_{\mathrm{i}} \\
& (27.64)^{* *} \quad(7.89)^{* * *} \\
& \mathbf{F}=(62.29) * * \quad \mathbf{R}^{-2}=\mathbf{0 . 7 7 3}
\end{aligned}
$$

كما اتضح أن الميزان التجاري للإمارات تراوحت بين حد أدنى بلغ حوالي ا.ب مليار دولار في ري

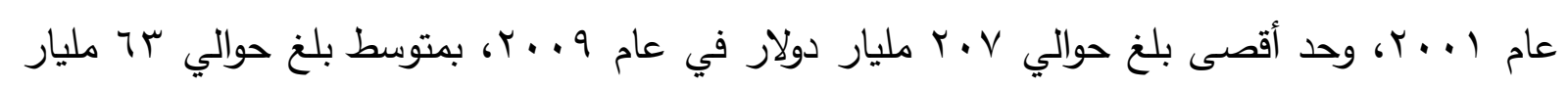
دولار خلال فترة الدراسة. وبتقدير معادلة الإتجاه الزمني العام للميزان التجاري للإمارات خلال فترة الدراسة تبين أنه ارتفع بمعدل نمو سنوي معنوي إحصائياً عند المستوى الإحتمالي ه... ٪ بلغ نحو 9.9 ٪ خلال نفس الفترة وقد بلغت قيمة معامل التحديد المعدل حوالي ب.9 1\% مما يدل على أن النموذج يفسر حوالي 9 ( ٪ فقط من التغيرات التي تحدث للميزان التجاري للإمارات كما يتضح من المعادلة التالية: 


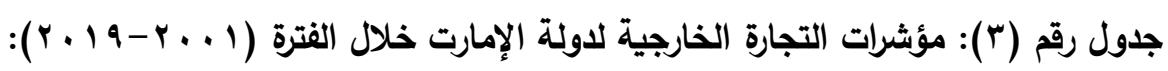

القيمة بالمليار دولار

\begin{tabular}{|c|c|c|c|c|c|}
\hline نسبة تغطية الصادر ات & التجاري & إجمالي التبادل & واردات & صادر ات & السنو ات \\
\hline 107.0 & 2.1 & 63.2 & 30.5 & 32.7 & 2001 \\
\hline 122.3 & 9.5 & 94.8 & 42.7 & 52.2 & 2002 \\
\hline 128.9 & 15.1 & 119.2 & 52.1 & 67.1 & 2003 \\
\hline 125.8 & 18.6 & 162.7 & 72.1 & 90.6 & 2004 \\
\hline 142.9 & 34.6 & 196.3 & 80.8 & 115.5 & 2005 \\
\hline 145.6 & 44.6 & 240.4 & 97.9 & 142.5 & 2006 \\
\hline 123.3 & 29.6 & 283.6 & 127.0 & 156.6 & 2007 \\
\hline 199.5 & 174.6 & 525.6 & 175.5 & 350.1 & 2008 \\
\hline 226.0 & 207.0 & 535.5 & 164.3 & 371.2 & 2009 \\
\hline 183.4 & 156.0 & 530.0 & 187.0 & 343.0 & 2010 \\
\hline 142.4 & 89.5 & 511.4 & 210.9 & 300.5 & 2011 \\
\hline 113.0 & 34.0 & 556.1 & 261.0 & 295.0 & 2012 \\
\hline 106.3 & 18.6 & 608.5 & 295.0 & 313.5 & 2013 \\
\hline 107.5 & 22.4 & 619.6 & 298.6 & 321.0 & 2014 \\
\hline 110.1 & 28.9 & 603.0 & 287.0 & 315.9 & 2015 \\
\hline 109.0 & 24.3 & 565.8 & 270.8 & 295.0 & 2016 \\
\hline 114.6 & 39.8 & 587.3 & 273.7 & 313.6 & 2017 \\
\hline 148.3 & 126.4 & 649.4 & 261.5 & 387.9 & 2018 \\
\hline 145.3 & 121.4 & 657.3 & 267.9 & 389.4 & 2019 \\
\hline 133.6 & 63.01 & 426.83 & 181.9 & 244.92 & متوسط \\
\hline
\end{tabular}

المصدر: Trade statistics for international business development Trade map

$$
\begin{aligned}
& \operatorname{Ln} \hat{Y}_{i}=2.633+0.099 T_{i} \\
& \mathbf{F}=(5.29)^{*} \stackrel{(5.36)^{* *}}{\mathbf{R}^{-2}=0.192}
\end{aligned}
$$

كما تثير بيانات الجدول أن نسبة تغطية الصادرات للواردات للإمارات تراوحت بين حد أدنى بلغ

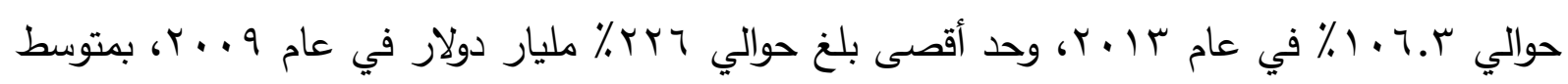
هندسي بلغ حوالي 7. بـ ا ٪ خلال فترة الدراسة. وبتقدير معادلة الإتجاه الزمني العام لنسبة تغطية الصادرات للواردات للإمارات خلال فترة الدراسة

تبين عدم معنوية هذا المتغير •

مما سبق يتبين أن الميزان التجاري للإمارات يحقق فائض خلال فترة الدراسة علماً بأن صادراتها تزداد بمعدل نمو يقترب كثيراً من معدل نمو وارداتها خلال نفس الفترة. 
ץ- تطور التجارة الخارجية لاولة الكويت وأهميتها النسبية لاول مجلس التعاون الخليجي خلال الفترة

$$
\text { من (1) }
$$

باستعراض البيانات الواردة بجدول رقم (ع) تبين أن إجمالي قيمة صادرات الكويت تراوحت بين حد أدنى بلغ حوالي ؟. 10 مليار دولار تمثل نحو \&؟.9\% من إجمالي صادرات دول مجلس التعاون في

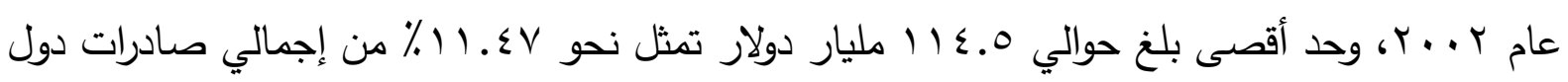

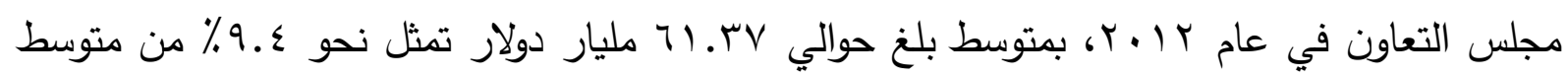
إجمالي صادرات دول مجلس التعاون خلال فترة الدراسة. وبتقدير معادلة الإتجاه الزمني العام لإجمالي قيمة صادرات الكويت خلال فترة الدراسة تبين أنه ارتفع بمعدل نمو سنوي معنوي إحصائياً عند المستوى الإحتمالي ا...٪ بلغ نحو r. خـ خلال نفس

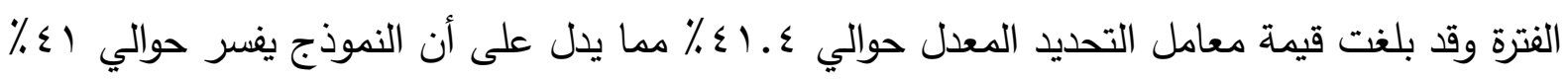
من التغيرات التي تحدث لإجمالي قيمة صادرات الكويت كما يتضح من المعادلة التالية:

$$
\begin{gathered}
\operatorname{Ln} \hat{Y}_{\mathbf{i}}=3.233+0.073 \mathrm{~T}_{\mathrm{i}} \\
\begin{array}{c}
(14.39) * * \\
\mathbf{F}=(13.71)^{* * *}
\end{array} \\
\mathbf{R}^{-2}=\mathbf{0 . 4 1 4}
\end{gathered}
$$

\begin{tabular}{|c|c|c|c|c|c|}
\hline نسبة تلغطية الصنادرات & التجاري & إجمالي التبادل & واردات & صادرات & السنوات \\
\hline 205.4 & 8.3 & 24.0 & 7.9 & 16.2 & 2001 \\
\hline 171.0 & 6.4 & 24.4 & 9.0 & 15.4 & 2002 \\
\hline 187.8 & 9.6 & 31.6 & 11.0 & 20.6 & 2003 \\
\hline 226.8 & 16.0 & 41.3 & 12.6 & 28.6 & 2004 \\
\hline 272.7 & 24.8 & 53.5 & 14.4 & 39.1 & 2005 \\
\hline 324.9 & 38.8 & 73.2 & 17.2 & 56.0 & 2006 \\
\hline 293.5 & 41.3 & 84.1 & 21.4 & 62.7 & 2007 \\
\hline 352.1 & 62.6 & 112.3 & 24.8 & 87.5 & 2008 \\
\hline 261.0 & 32.1 & 71.9 & 19.9 & 52.0 & 2009 \\
\hline 276.3 & 40.0 & 85.4 & 22.7 & 62.7 & 2010 \\
\hline 408.5 & 77.6 & 127.8 & 25.1 & 102.7 & 2011 \\
\hline 420.1 & 87.3 & 141.8 & 27.3 & 114.5 & 2012 \\
\hline 389.5 & 84.8 & 143.4 & 29.3 & 114.1 & 2013 \\
\hline 321.2 & 69.6 & 132.6 & 31.5 & 101.1 & 2014 \\
\hline
\end{tabular}

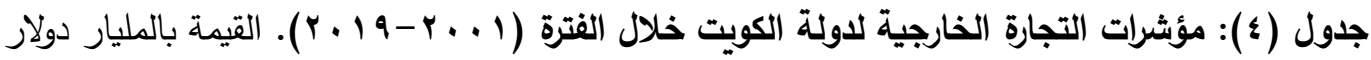


مجلة البحوث والاراسات الإفريقية ودول حوض النيل - جامعة أسون - المجلد (r) - العدد (r) - يناير ( r · م م)

\begin{tabular}{l|l|l|l|l|l}
\hline 172.9 & 23.3 & 87.1 & 31.9 & 55.2 & 2015 \\
150.0 & 15.4 & 77.1 & 30.8 & 46.2 & 2016 \\
163.8 & 21.4 & 88.6 & 33.6 & 55.0 & 2017 \\
200.6 & 36.1 & 107.8 & 35.9 & 71.9 & 2018 \\
192.3 & 31.0 & 98.0 & 33.5 & 64.5 & 2019 \\
\hline \hline 249.4 & 38.23 & 84.52 & 23.1 & 61.37 & منو \\
\hline \hline
\end{tabular}

المصدر: Trade statistics for international business development Trade map

كما تبين أن إجمالي قيمة واردات الكويت تراوحت بين حد أدنى بلغ حوالي V.9 مليار دولار

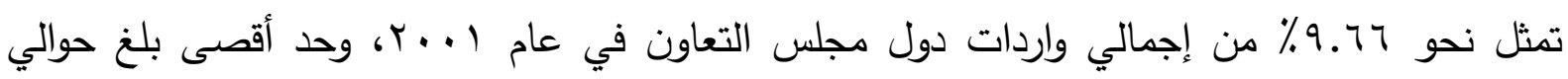

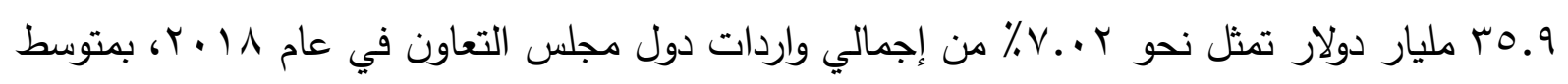
بلغ حوالي ا.بr مليار دولار تمثل نحو 9٪.9\% من متوسط إجمالي واردات دول مجلس التعاون خلال فترة الدراسة. وبتقدير معادلة الإتجاه الزمني العام لإجمالي قيمة واردات الكويت خلال فترة الدراسة تبين أنه ارتفع بمعدل نمو سنوي معنوي إحصائياً عند المستوى الإحتمالي ا ... ٪ بلغ نحو 9. ٪ خلال نفس

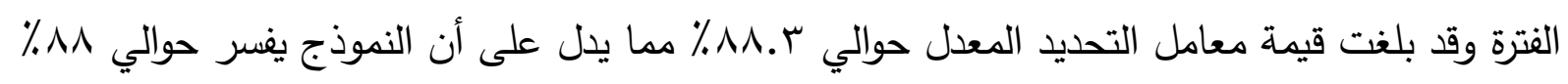
من التغيرات التي تحدث لإجمالي قيمة واردات الكويت كما يتضح من المعادلة التالية:

$$
\begin{aligned}
& \operatorname{Ln} \hat{Y}_{i}=2.260+0.079 T_{i} \\
& (29.39) * * \quad(11.71) * * \\
& \mathbf{F}=(\mathbf{1 3 7 . 1 5})^{* *} \quad \mathbf{R}^{-2}=\mathbf{0 . 8 8 3}
\end{aligned}
$$

واتضح أن إجمالي قيمة التبادل التجاري للكويت تراوحت بين حد أدنى بلغ حوالي 24 مليار

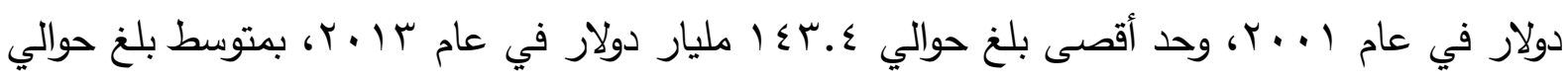

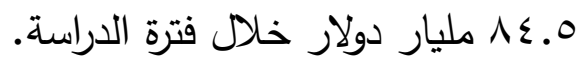
وبتقدير معادلة الإتجاه الزمني العام لإجمالي قيمة التبادل التجاري للكويت خلال فترة الدراسة تبين أنه ارتفع بمعدل نمو سنوي معنوي إحصائياً عند المستوى الإحتمالي ا ... ٪ بلغ نحو ه. ٪ خلال 
نفس الفترة وقد بلغت قيمة معامل التحديد المعدل حوالي V. \&ه م ما يدل على أن النموذج يفسر حوالي \% \% من التغيرات التي تحدث لإجمالي قيمة التبادل التجاري للكويت كما يتضح من المعادلة التالية:

$$
\begin{gathered}
\operatorname{Ln} \hat{\mathbf{Y}}_{\mathbf{i}}=\begin{array}{c}
3.558+0.075 \mathrm{~T}_{\mathbf{i}} \\
(32.62)^{* * *}
\end{array} \\
\mathbf{F}=(\mathbf{7 . 8 0})^{* *} \\
\left.\mathbf{R}^{-2}=\mathbf{0 . 5 4 7}\right)^{* * *}
\end{gathered}
$$

كما اتضح أن الميزان التجاري للكويت تراوح بين حد أدنى بلغ حوالي ؟.7 مليار دولار في عام

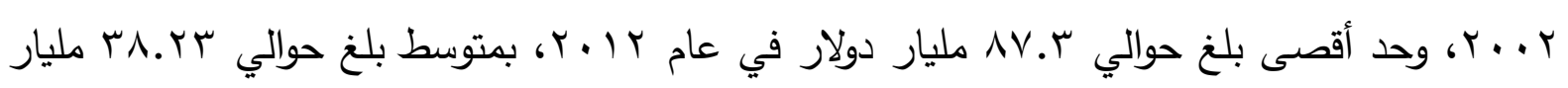
دولار خلال فترة الدراسة. وبتقدير معادلة الإتجاه الزمني العام للميزان التجاري للكويت خلال فترة الدراسة تبين عدم ثبوت معنوية هذا المتغير. كما تشير بيانات الجدول أن نسبة تغطية الصادرات للواردات لدولة الكويت تراوحت بين جد أدنى

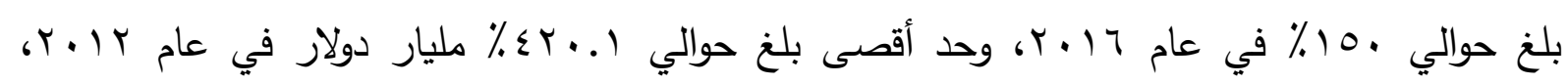
بمتوسط هندسي بلغ حوالي ؟ ؟9 ؟ ٪ خلال فترة الدراسة. وبتقدير معادلة الإتجاه الزمني العام لنسبة تغطية الصادرات للواردات لدولة الكويت خلال فترة الدراسة تبين عدم ثبوت معنوية هذا المتغير. مما سبق يتبين أن الميزان التجاري للكويت يحقق فائض خلال فترة الدراسة مع ملاحظة معدل نمو صادراتها يقترب كثيراً من معدل نمو وارداتها خلال نفس الفترة. ع - تطور التجارة الخارجية لدوية البحرين وأهميتها النسبية لاول مجلس التعاون الخليجي خلال الفترة

$$
\text { من }
$$

باستعراض البيانات الواردة بجدول رقم (ه) تبين أن إجمالي قيمة صادرات البحرين تراوحت بين حد أدنى بلغ حوالي 0.7 مليار دولار تمثل نحو بـ.؟\% من إجمالي صادرات دول مجلس التعاون في 


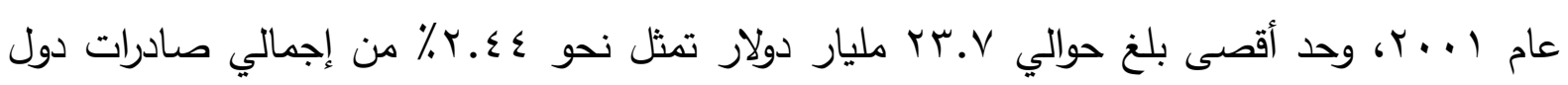

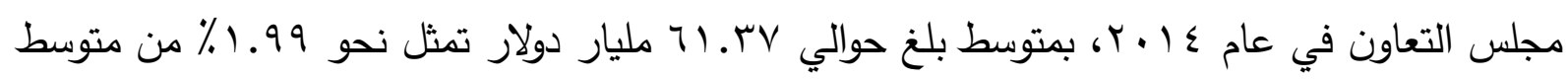
إجمالي صادرات دول مجلس التعاون خلال فترة الدراسة.

وبتقدير معادلة الإتجاه الزمني العام لإجمالي قيمة صادرات البحرين خلال فترة الدراسة تبين أنه ارتفع بمعل نمو سنوي معنوي إحصائياً عند المستوى الإحتمالي ا...٪ بلغ نحو ـ٪\% خلال نفس الفترة وقد بلغت قيمة معامل التحديد المعدل حوالي بـء مما يدل على أن النموذج يفسر حوالي بـ \% من التغيرات التي تحدث لإجمالي قيمة صادرات البحرين كما يتضح من المعادلة التالية:

$$
\begin{aligned}
& \operatorname{Ln} \hat{Y}_{i}=1.973+0.051 T_{i} \\
& \left.\mathbf{F}=(14.03)^{* * * 71}\right)^{* *} \begin{array}{r}
(3.75)^{* * *} \\
\mathbf{R}^{-2}=\mathbf{0 . 4 2 0}
\end{array}
\end{aligned}
$$

كما تبين أن إجمالي قيمة واردات البحرين تراوحت بين حد أدنى بلغ حوالي ب.؛ مليار دولار

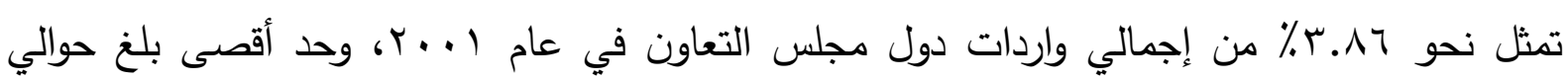

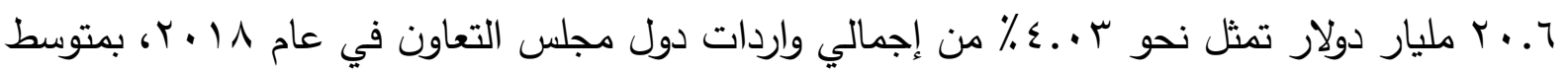

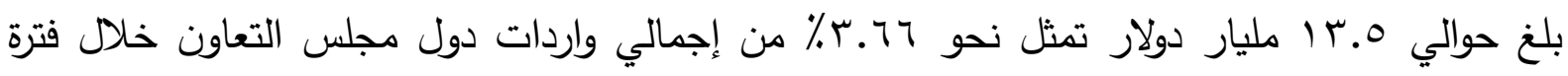
الدراسة. وبتقدير معادلة الإتجاه الزمني العام لإجمالي قيمة واردات البحرين خلال فترة الدراسة تبين أنه ارتفع بمعدل نمو سنوي معنوي إحصائياً عند المستوى الإحتمالي (... بلغ نحو ^.؟٪ خلال نفس

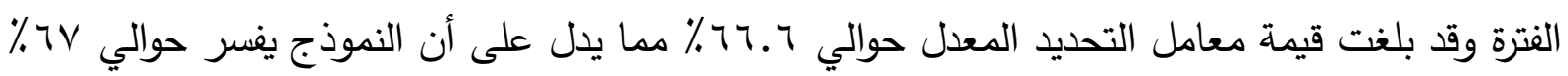
من التغيرات التي تحدث لإجمالي قيمة واردات البحرين كما يتضح من المعادلة التالية:

$$
\begin{gathered}
\operatorname{Ln} \hat{Y}_{i}=1.786+0.068 T_{i} \\
\begin{array}{cc}
(13.60) * * & (6.24) * * \\
F=(38.93)^{* * *} & R^{-2}=0.666
\end{array}
\end{gathered}
$$


واتضح أن إجمالي قيمة التبادل التجاري للبحربن تراوحت بين حد أدنى بلغ حوالي 9.8 مليار

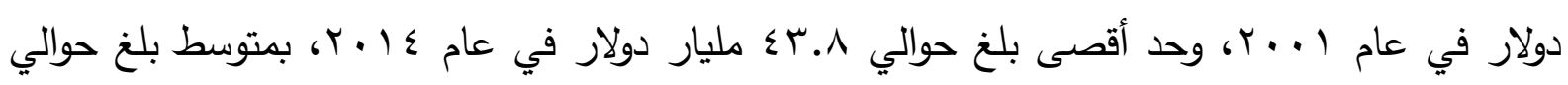

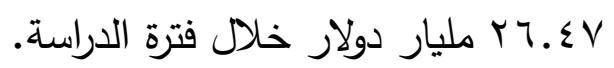
وبتقدير معادلة الإتجاه الزمني العام لإجمالي قيمة التبادل التجاري للبحرين خلال فترة الدراسة تبين أنه ارتفع بمعدل نمو سنوي معنوي إحصائياً عند المستوى الإحتمالي ا ... ٪ بلغ نحو \.ـ ٪ خلا نفس الفترة وقد بلغت قيمة معامل التحديد المعدل حوالي V.بr٪\% مما يدل على أن النموذج يفسر حوالي ع ٪ \% من التغيرات التي تحدث لإجمالي قيمة التبادل التجاري للبحرين كما يتضح من المعادلة التالية:

$$
\begin{aligned}
& \operatorname{Ln} \hat{Y}_{i}=2.664+0.047 T_{i} \\
& (15.34)^{* * *}(3.27)^{* * *} \\
& \mathbf{F}=(\mathbf{1 0 . 6 8})^{* *} \quad \mathbf{R}^{-2}=\mathbf{0 . 3 3 7}
\end{aligned}
$$

كما اتضح أن الميزان التجاري للبحرين تراوح بين حد أدنى بلغ حوالي (6.2-) مليار دولار في

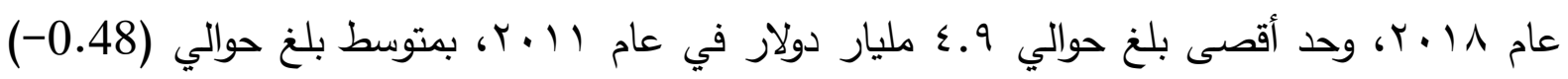

\begin{tabular}{|c|c|c|c|c|c|}
\hline نسبة تلغطية الصنادر ات & التجاري & إلجمالي التبادل & واردات & صادرات & السنوات \\
\hline 129.2 & 1.3 & 9.8 & 4.3 & 5.6 & 2001 \\
\hline 115.6 & 0.8 & 10.8 & 5.0 & 5.8 & 2002 \\
\hline 117.2 & 1.0 & 12.3 & 5.7 & 6.6 & 2003 \\
\hline 114.2 & 0.9 & 14.1 & 6.6 & 7.5 & 2004 \\
\hline 109.6 & 0.9 & 19.6 & 9.3 & 10.2 & 2005 \\
\hline 130.2 & 2.7 & 20.6 & 9.0 & 11.7 & 2006 \\
\hline 118.7 & 2.1 & 25.2 & 11.5 & 13.7 & 2007 \\
\hline 71.0 & -5.3 & 31.5 & 18.4 & 13.1 & 2008 \\
\hline 69.9 & -3.6 & 20.4 & 12.0 & 8.4 & 2009 \\
\hline 100.4 & 0.1 & 32.1 & 16.0 & 16.1 & 2010 \\
\hline 127.9 & 4.9 & 40.2 & 17.6 & 22.6 & 2011 \\
\hline 116.6 & 2.4 & 30.9 & 14.2 & 16.6 & 2012 \\
\hline 107.6 & 1.4 & 38.7 & 18.6 & 20.0 & 2013 \\
\hline
\end{tabular}
مليار دولار خلال فترة الدراسة.

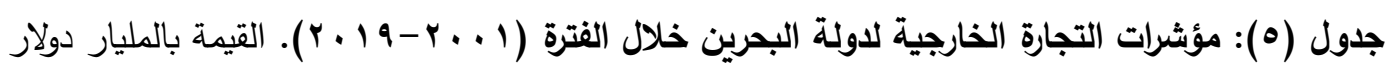


مجلة البحوث والدراسات الإفريقية ودول حوض النيل - جامعة أسون - المجلد (r) - العدد (Y) - يناير ( Y r م م)

\begin{tabular}{l|l|l|l|l|l}
\hline 118.3 & 3.7 & 43.8 & 20.1 & 23.7 & 2014 \\
84.4 & -2.6 & 30.2 & 16.4 & 13.8 & 2015 \\
71.7 & -4.2 & 25.3 & 14.7 & 10.6 & 2016 \\
71.8 & -4.9 & 29.9 & 17.4 & 12.5 & 2017 \\
69.7 & -6.2 & 34.9 & 20.6 & 14.3 & 2018 \\
76.2 & -4.4 & 32.8 & 18.6 & 14.2 & 2019 \\
\hline \hline 98.4 & -0.48 & 26.47 & 13.5 & 13.00 & من \\
\hline \hline
\end{tabular}

المصدر: Trade statistics for international business development Trade map

وبتقدير معادلة الإتجاه الزمني العام للميزان التجاري للبحرين خلال فترة الدراسة تبين عدم ثبوت

معنوية هذا المتغير

كما تشير بيانات الجدول أن نسبة تغطية الصادرات للواردات لدولة البحرين تراوحت بين جد

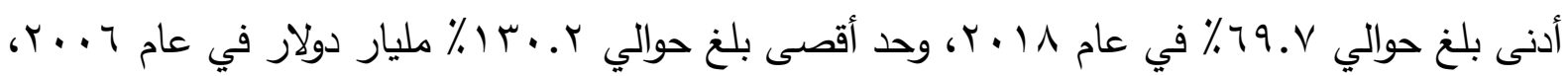
بمتوسط هندسي بلغ حوالي ؟ ؟ ؟ \% خلال فترة الدراسة. وبتقدير معادلة الإتجاه الزمني العام لنسبة تغطية الصادرات للواردات لدولة البحرين خلال فترة

الدراسة تبين أنها انخفضت بمعدل انخفاض سنوي معنوي إحصائياً عند المستوى الإحتمالي ا... ٪ بلغ نحو Y.Y\% خلال نفس الفترة وقد بلغت قيمة معامل التحديد المعدل حوالي ؟.بr\% مما يدل على أن النموذج يفسر حوالي جץ\% من التغيرات التي تحدث لإجمالي قيمة التبادل التجاري للبحرين كما يتضح من المعادلة التالية: - من

$$
\begin{aligned}
& \operatorname{Ln} \hat{Y}_{i}=2.664-0.027 T_{i} \\
& \mathbf{F}=(\mathbf{1 1 . 2})^{* *} \mathbf{R}^{-2}=\mathbf{0 . 3 6 2} 2
\end{aligned}
$$

مما سبق يتبين أن الميزان التجاري للبحرين حقق فائضاً في بعض السنوات، وحقق عجزاً في أغلب السنوات موضع الدراسة نتيجة انخفاض قيمة صادراتها عن قيمة وارداتها في تلك السنوات. ه - تطور التجارة الخارجية لدولة قطر وأهميتها النسبية لدول مجلس التعاون الخليجي خلال الفترة

$$
\text { من (1) }
$$


باستعراض البيانات الواردة بجدول رقم (؟) تبين أن إجمالي قيمة صادرات قطر تراوحت بين حد

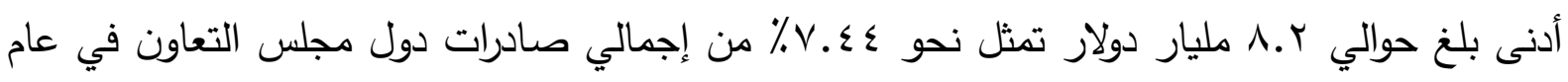

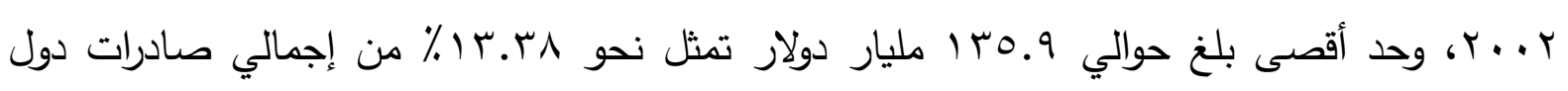

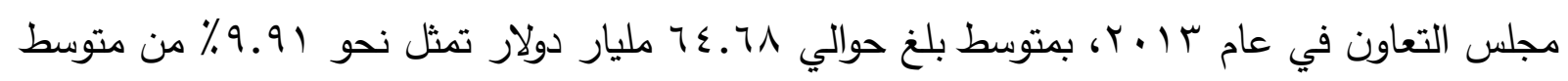
إجمالي صادرات دول مجلس التعاون خلال فترة الدراسة.

وبتقدير معادلة الإتجاه الزمني العام لإجمالي قيمة صادرات قطر خلال فترة الدراسة تبين أنه

ارتفع بمعدل نمو سنوي معنوي إحصائياً عند المستوى الإحتمالي ا ... ٪ بلغ نحو ^.ب ا٪ خلال نفس

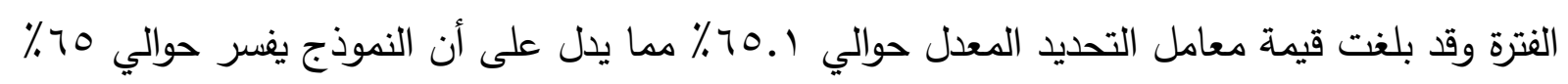
من التغيرات التي تحدث لإجمالي قيمة صادرات قطر كما يتضح من المعادلة التالية:

$$
\begin{aligned}
& \operatorname{Ln} \hat{Y}_{i}=2.607+0.128 T_{i} \\
& (10.53)^{* *} \quad(5.88)^{* * *} \\
& \mathbf{F}=(\mathbf{3 4 . 5 7})^{* *} \quad \mathbf{R}^{-2}=\mathbf{0 . 6 5 1}
\end{aligned}
$$

\begin{tabular}{|c|c|c|c|c|c|}
\hline نسبة تلغطية الصنادر ات & التجبزي & إجمالي التبادل & واردات & صادرات & السنو ات \\
\hline 284.9 & 6.9 & 14.5 & 3.8 & 10.7 & 2001 \\
\hline 203.1 & 4.2 & 12.3 & 4.1 & 8.2 & 2002 \\
\hline 252.8 & 7.5 & 17.3 & 4.9 & 12.4 & 2003 \\
\hline 311.2 & 12.7 & 24.7 & 6.0 & 18.7 & 2004 \\
\hline 246.1 & 14.7 & 34.8 & 10.1 & 24.8 & 2005 \\
\hline 207.1 & 17.6 & 50.5 & 16.4 & 34.1 & 2006 \\
\hline 179.3 & 18.6 & 65.4 & 23.4 & 42.0 & 2007 \\
\hline 241.2 & 39.4 & 95.2 & 27.9 & 67.3 & 2008 \\
\hline 192.6 & 23.1 & 72.9 & 24.9 & 48.0 & 2009 \\
\hline 322.6 & 51.7 & 98.2 & 23.2 & 75.0 & 2010 \\
\hline 503.5 & 90.1 & 134.8 & 22.3 & 112.4 & 2011 \\
\hline 509.9 & 106.9 & 159.1 & 26.1 & 133.0 & 2012 \\
\hline 502.5 & 108.8 & 162.9 & 27.0 & 135.9 & 2013 \\
\hline 431.2 & 100.9 & 161.9 & 30.5 & 131.4 & 2014 \\
\hline 239.1 & 45.4 & 110.6 & 32.6 & 78.0 & 2015 \\
\hline 232.7 & 41.5 & 104.0 & 31.3 & 72.7 & 2016 \\
\hline 225.8 & 37.6 & 97.4 & 29.9 & 67.5 & 2017 \\
\hline
\end{tabular}

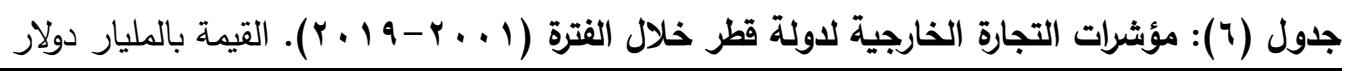




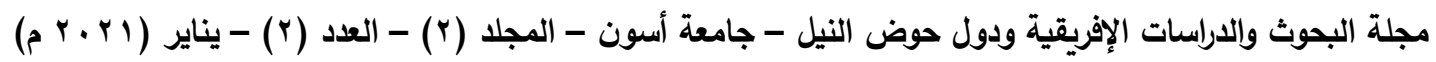

\begin{tabular}{l|c|c|c|c|c}
\hline 264.7 & 52.2 & 115.6 & 31.7 & 83.9 & 2018 \\
250.0 & 43.8 & 102.1 & 29.2 & 72.9 & 2019 \\
\hline \hline 278.8 & 43.35 & 86.01 & 21.3 & 64.68 & s. \\
\hline \hline
\end{tabular}

المصدر: Trade statistics for international business development Trade map

كما تبين أن إجمالي قيمة واردات قطر تراوحت بين حد أدنى بلغ حوالي ^.؟ مليار دولار تمثل

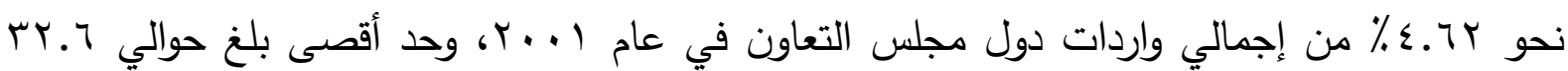

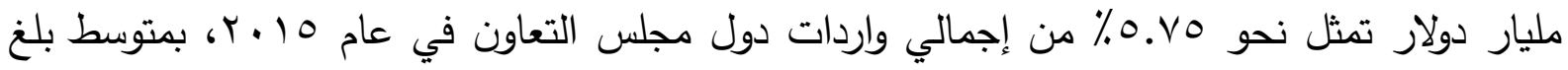

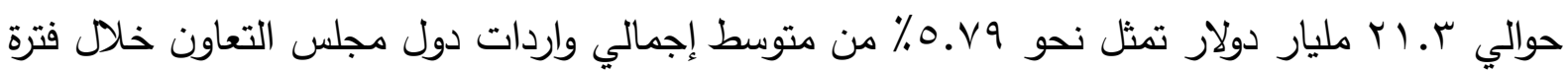

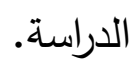

وبتقدير معادلة الإتجاه الزمني العام لإجمالي قيمة واردات قطر خلال فترة الدراسة تبين أنه ارتفع

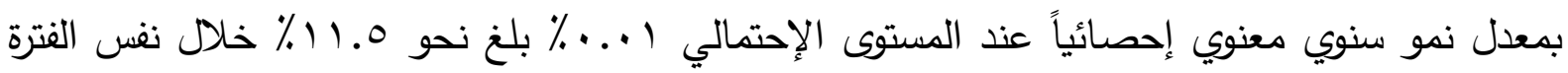

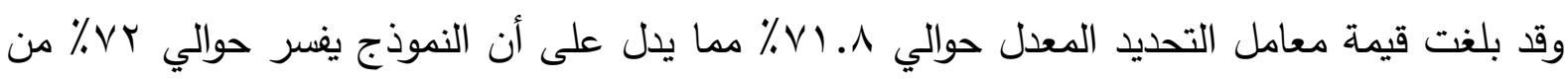
التغيرات التي تحدث لإجمالي قيمة واردات قطر كما يتضح من المعادلة التالية: $\operatorname{Ln} \hat{Y}_{i}=1.704+0.115 T_{i}$

$(29.39) * * \quad(6.84) * *$

$$
\mathbf{F}=(\mathbf{4 6 . 8 1})^{* *} \quad \mathbf{R}^{-2}=\mathbf{0 . 7 1 8}
$$

واتضح أن إجمالي قيمة التبادل التجاري لقطر تراوحت بين حد أدنى بلغ حوالي 12.3 مليار

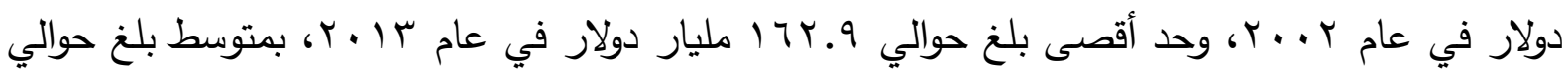

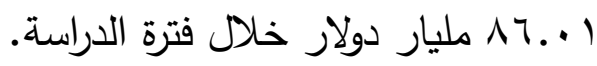

وبتقدير معادلة الإتجاه الزمني العام لإجمالي قيمة التبادل التجاري لقطر خلال فترة الدراسة تبين

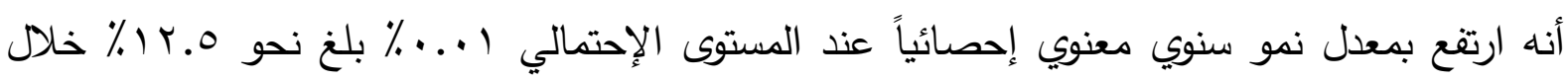

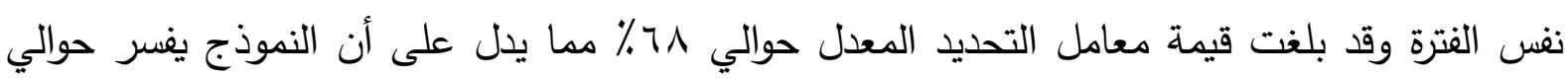

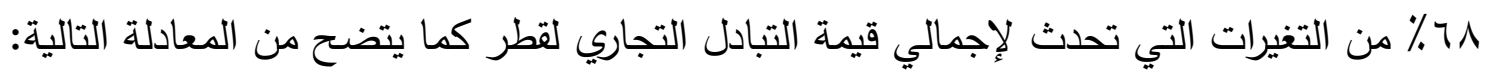

$$
\begin{aligned}
& \operatorname{Ln} \hat{Y}_{i}=2.953+0.125 T_{i}
\end{aligned}
$$

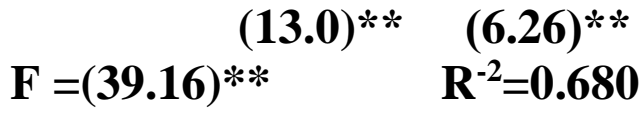

كما اتضح أن الميزان التجاري لقطر تراوح بين حد أدنى بلغ حوالي r.؛ مليار دولار في عام

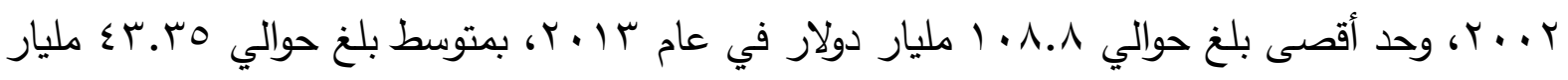
دولار خلال فترة الدراسة. وبتقدير معادلة الإتجاه الزمني العام للميزان التجاري لقطر خلال فترة الدراسة تبين أنه ارتفع

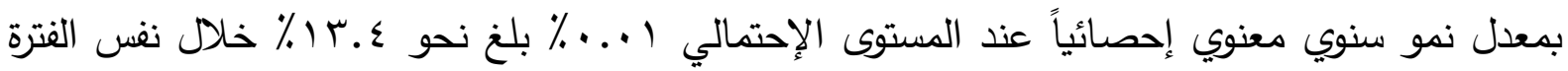




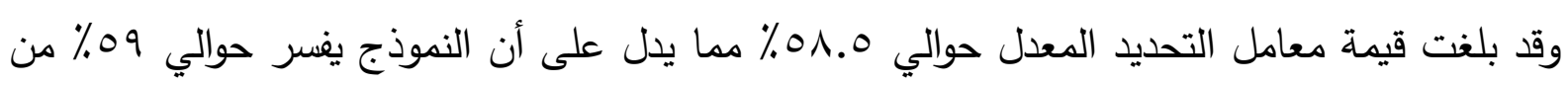
التغيرات التي تحدث للميزان التجاري القطري كما يتضح من المعادلة التالية:

$$
\begin{array}{cc}
\operatorname{Ln} \hat{\mathbf{Y}}_{\mathbf{i}}=\underset{(6.89) * *}{2.055}+0.134 \mathrm{~T}_{\mathbf{i}} & (5.13) * * \\
\mathbf{F}=(\mathbf{2 6 . 3 3})^{* *} & \mathbf{R}^{-2}=\mathbf{0 . 5 8 5}
\end{array}
$$

كما تثير بيانات الجدول أن نسبة تغطية الصادرات للواردات لدولة قطر تراوحت بين جد أدنى

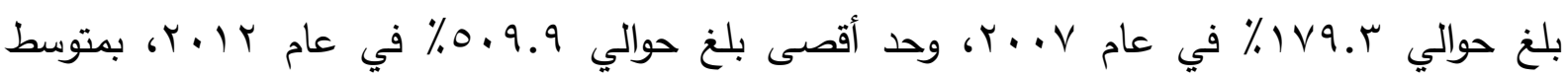

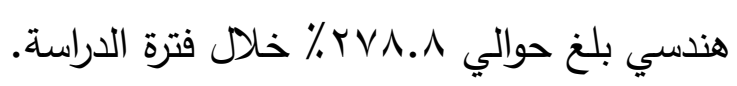
وبتقدير معادلة الإتجاه الزمني العام لنسبة تغطية الصادرات للواردات لدولة قطر خلة خلال فترة الدراسة تبين عدم ثبوت معنوية هذا المتغير •

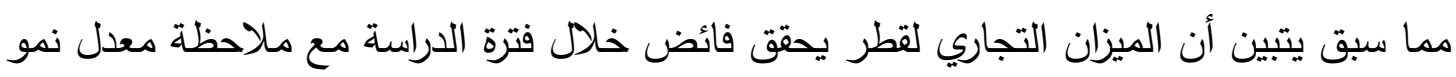

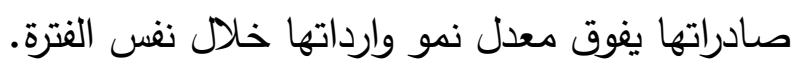

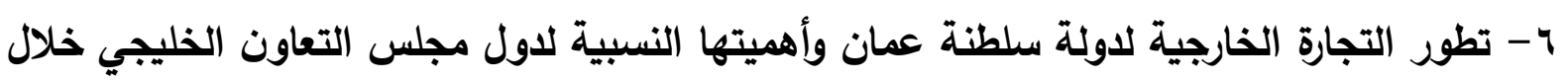

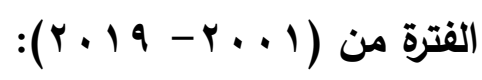

باستعراض البيانات الواردة بجدول رقم V) تبين أن إجمالي قيمة صادرات سلطنة عمان تراوحت

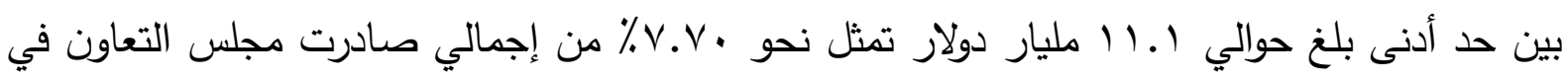

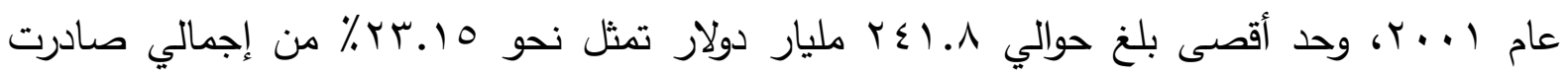

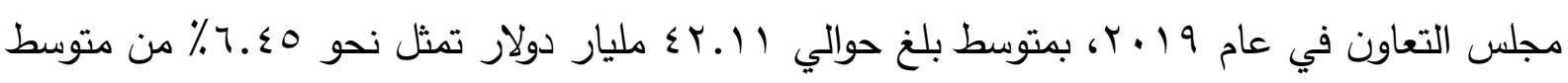
إجمالي صادرت مجلس التعاون خلال فترة الدراسة.

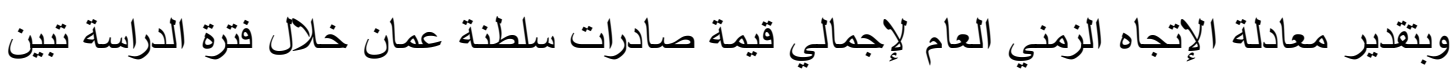

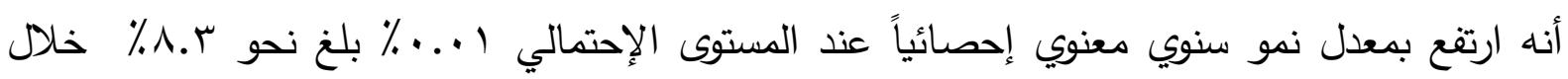

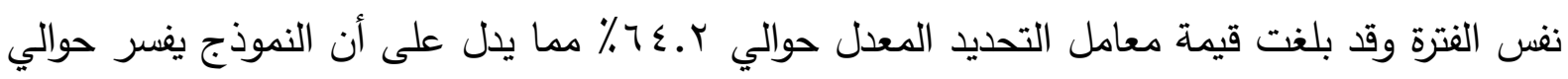

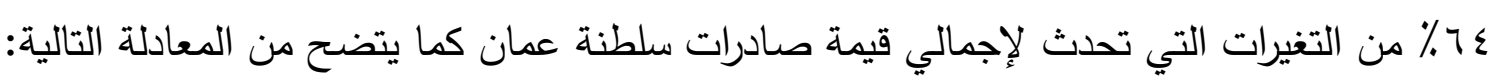

$$
\begin{aligned}
& \operatorname{Ln} \hat{Y}_{i}=2.519+0.083 T_{i}
\end{aligned}
$$

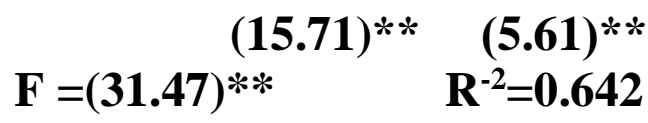

كما تبين أن إجمالي قيمة واردات سلطنة عمان تراوحت بين حد أدنى بلغ حوالي ـ.ـ مليار

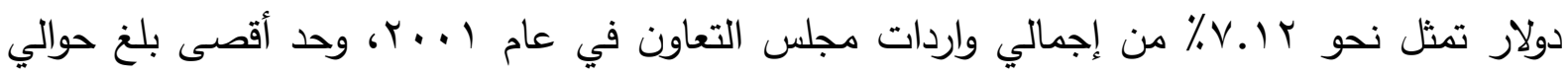

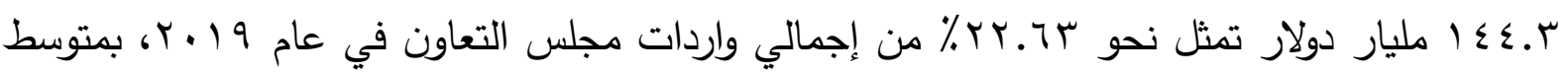


بلغ حوالي Y.Y. مليار دولار تمثل نحو 91. ؟\% من متوسط إجمالي واردات مجلس التعاون خلال فترة

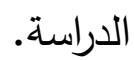

وبتقدير معادلة الإتجاه الزمني العام لإجمالي قيمة واردات سلطنة عمان خلال فترة الدراسة تبين

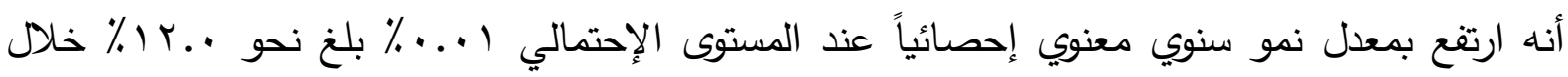

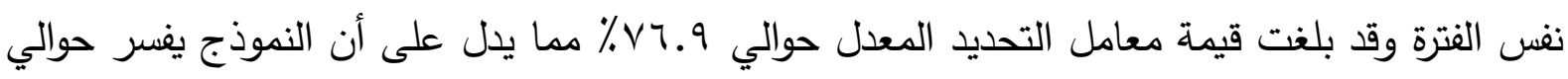
مV من التغيرات التي تحدث لإجمالي قيمة واردات سلطنة عمان كما يتضح من المعادلة التالية:

$$
\begin{aligned}
& \operatorname{Ln} \hat{\mathbf{Y}}_{\mathrm{i}}=1.713+0.120 \mathrm{~T}_{\mathrm{i}} \\
& (9.75)^{* *} \quad(7.81)^{* *} \\
& \mathbf{F}=(61.02)^{* *} \quad \mathbf{R}^{-2}=0.769
\end{aligned}
$$

واتضح أن إجمالي قيمة التبادل التجاري لسلطنة عمان تراوحت بين حد أدنى بلغ حوالي 16.9

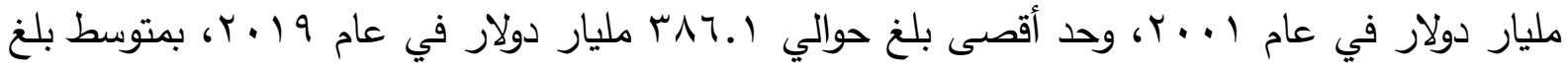
حوالي ^.^. مليار دولار خلال فترة الدراسة. وبتقدير معادلة الإتجاه الزمني العام لإجمالي قيمة التبادل التجاري لسلطنة عمان خلال فترة

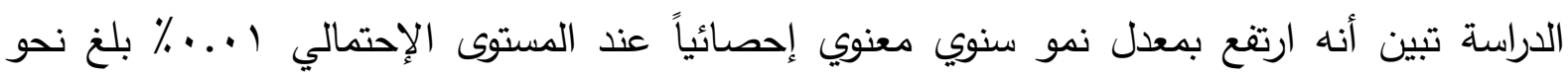

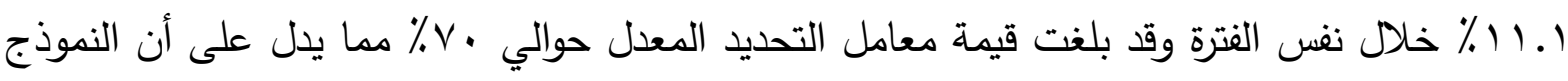

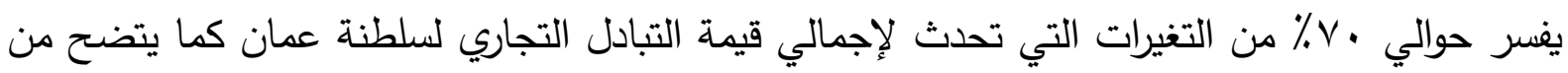

\begin{tabular}{|c|c|c|c|c|c|}
\hline نسبة تلغطية الصادرات & التجاري & إجمالي التبادل & واردات & صادرات & السنوات \\
\hline 191.0 & 5.3 & 16.9 & 5.8 & 11.1 & 2001 \\
\hline 187.1 & 5.2 & 17.2 & 6.0 & 11.2 & 2002 \\
\hline 179.3 & 5.4 & 19.0 & 6.8 & 12.2 & 2003 \\
\hline 152.1 & 4.6 & 22.2 & 8.8 & 13.4 & 2004 \\
\hline 208.4 & 9.7 & 27.7 & 9.0 & 18.7 & 2005 \\
\hline 195.6 & 10.5 & 32.6 & 11.0 & 21.6 & 2006 \\
\hline 154.1 & 8.7 & 40.7 & 16.0 & 24.7 & 2007 \\
\hline 164.5 & 14.8 & 60.6 & 22.9 & 37.7 & 2008 \\
\hline 154.9 & 9.8 & 45.5 & 17.9 & 27.7 & 2009 \\
\hline 185.1 & 16.8 & 56.4 & 19.8 & 36.6 & 2010 \\
\hline 199.4 & 23.5 & 70.7 & 23.6 & 47.1 & 2011 \\
\hline 185.4 & 24.0 & 80.3 & 28.1 & 52.1 & 2012 \\
\hline 158.7 & 20.2 & 88.8 & 34.3 & 54.5 & 2013 \\
\hline 181.6 & 23.9 & 82.5 & 29.3 & 53.2 & 2014 \\
\hline 110.1 & 2.9 & 60.9 & 29.0 & 31.9 & 2015 \\
\hline 129.7 & 6.9 & 53.2 & 23.1 & 30.0 & 2016 \\
\hline
\end{tabular}

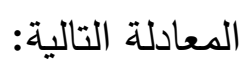

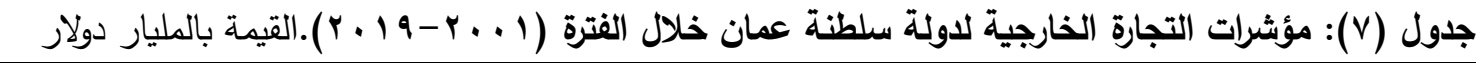


مجلة البحوث والدراسات الإفريقية ودول حوض النيل - جامعة أسون - المجلد (r) - العدد (r) - يناير ( r · م م)

\begin{tabular}{l|c|c|c|c|c}
\hline 124.5 & 6.5 & 59.3 & 26.4 & 32.9 & 2017 \\
162.1 & 16.0 & 67.5 & 25.8 & 41.8 & 2018 \\
167.5 & 97.5 & 386.1 & 144.3 & 241.8 & 2019 \\
\hline \hline 165.8 & 16.43 & 67.80 & 25.7 & 42.11 & מ من \\
\hline \hline
\end{tabular}

المصدر: Trade statistics for international business development Trade map

$$
\begin{gathered}
\operatorname{Ln} \hat{\mathbf{Y}}_{\mathbf{i}}=\underset{(32.62) * *}{2.787+0.111} \mathbf{T}_{\mathbf{i}}(\mathbf{7 . 8 0})^{* *} \\
\mathbf{F}=(\mathbf{4 3 . 0 6})^{* *} \quad \mathbf{R}^{-2}=\mathbf{0 . 7 0 0}
\end{gathered}
$$

كما اتضح أن الميزان التجاري لسلطنة عمان تراوح بين حد أدنى بلغ حوالي 9. ب مليار دولار في

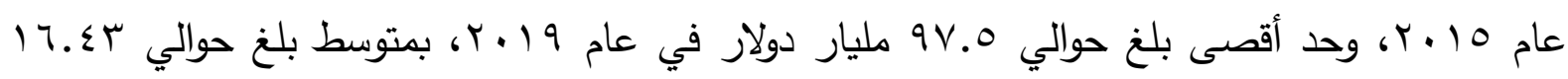
مليار دولار خلال فترة الدراسة. وبتقدير معادلة الإتجاه الزمني العام للميزان التجاري لسلطنة عمان خلال فترة الدراسة تبين أنه ارتفع بمعدل نمو سنوي معنوي إحصائياً عند المستوى الإحتمالي ه.. . ٪ بلغ نحو ر. ٪ خلال نفس

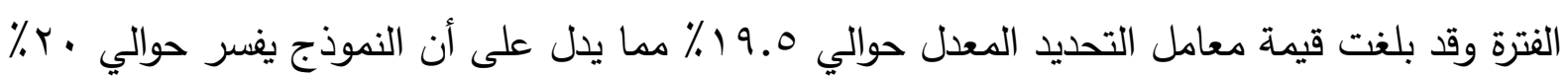
من التغيرات التي تحدث للميزان التجاري العماني كما يتضح من المعادلة التالية:

$$
\begin{array}{cc}
\operatorname{Ln} \hat{Y}_{i}=1.702 & +0.071 \mathrm{~T}_{\mathbf{i}} \\
(4.86) * * & (2.32)^{* *} \\
\mathrm{~F}=(5.36) * & R^{-2}=0.195
\end{array}
$$

كما تشير بيانات الجدول أن نسبة تغطية الصادرات للواردات لدولة سلطنة عمان تراوحت بين

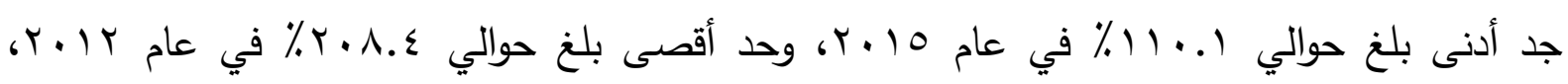
بمتوسط هندسي بلغ حوالي ع. § ؟ مليار دولار خلال فترة الدراسة. وبتقدير معادلة الإتجاه الزمني العام لنسبة تغطية الصادرات للواردات لدولة سلطنة عمان خلال فترة الدراسة تبين أنه انخفض بمعدل انخفاض سنوي معنوي إحصائياً عند المستوى الإحتمالي ه ... ٪

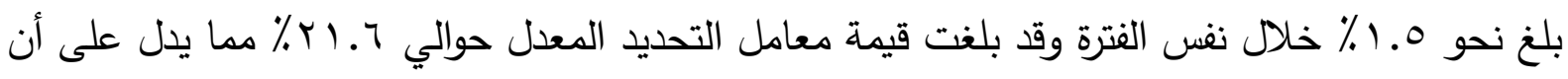
النموذج يفسر حوالي rr\% من التغيرات التي تحدث للميزان التجاري العماني كما يتضح من المعادلة

$$
\begin{aligned}
& \operatorname{Ln} \hat{Y}_{i}=5.264-0.015 T_{i} \\
& (73.43) * * \quad(-2.44) * \\
& \mathrm{~F}=(5.36) * \quad \mathbf{R}^{-2}=\mathbf{0 . 2 1 6}
\end{aligned}
$$

مما سبق يتبين أن الميزان التجاري لسلطنة عمان يحقق فائض خلال فترة الدراسة مع ملاحظة معدل نمو صادراتها يفوق معدل نمو وارداتها خلال نفس الفترة. يتضح من العرض السابق أن دولة البحرين هي الدولة الوحيدة بين دول مجلس التعاون الخليجي التي حقق ميزانها التجاري عجزاً في بعض فترات الدراسة، كما أمكن ترتيب دول مجلس التعاون من حيث 


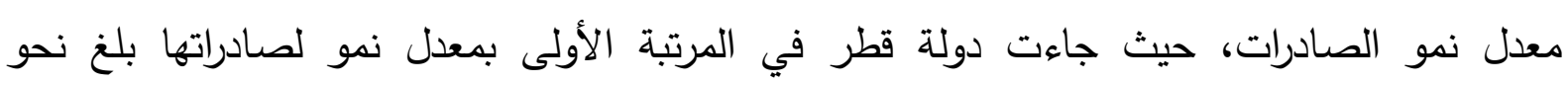

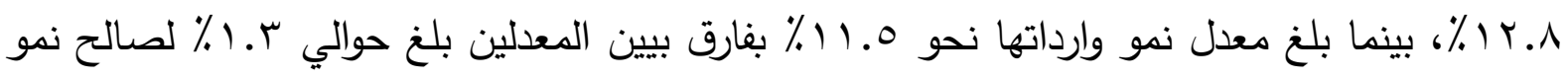

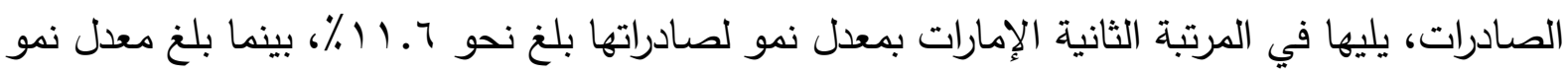

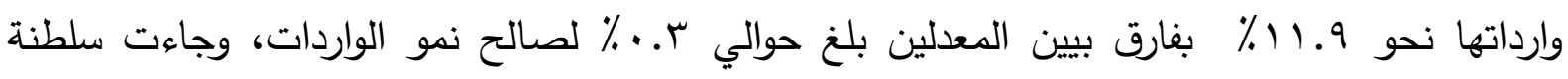

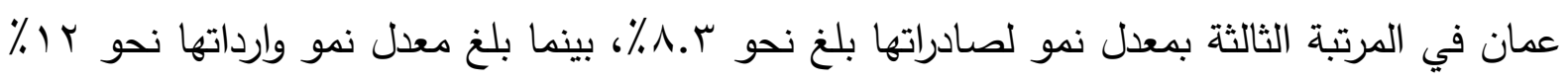

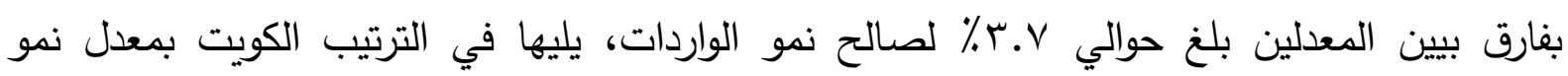

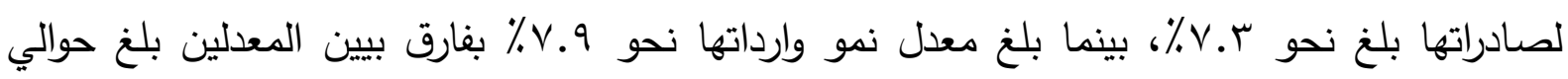

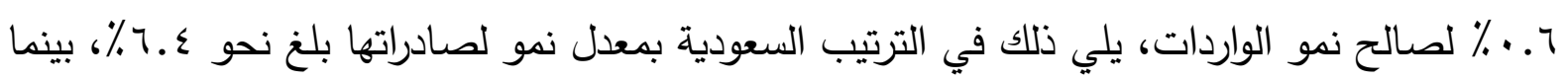

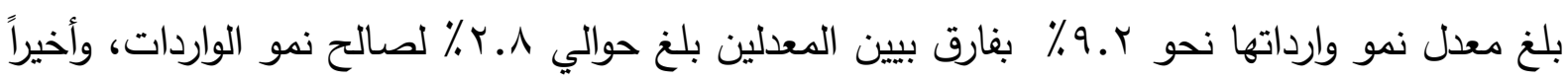

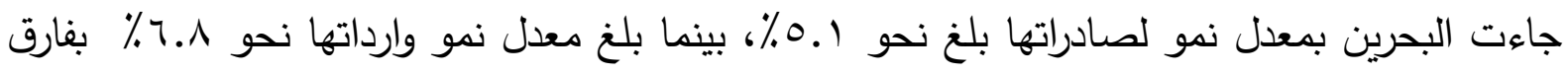

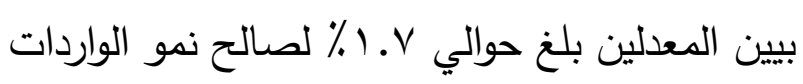

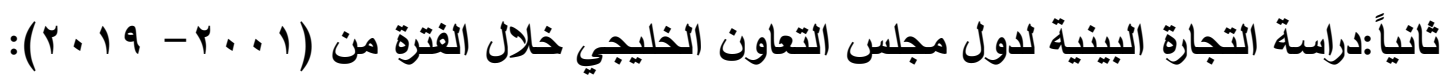
سوف يتم دراسة تطور التجارة البينية للسعودية والكويت مع دول مجلس التعارن التعاون الخليجي.

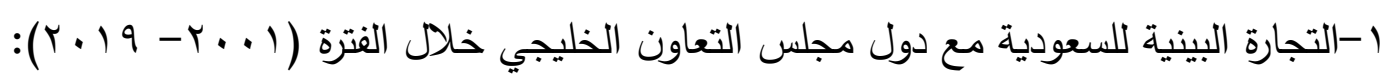

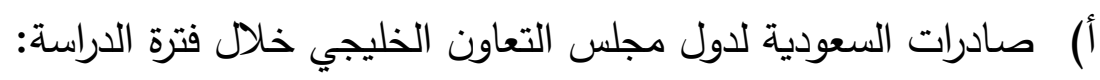

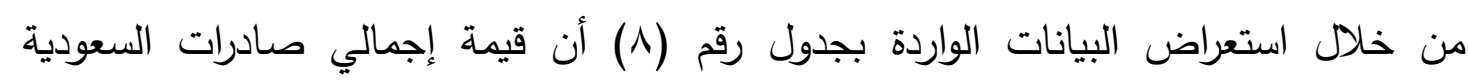

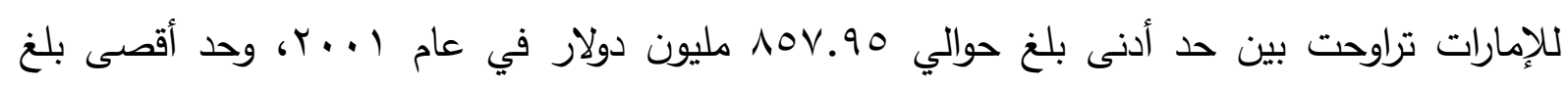

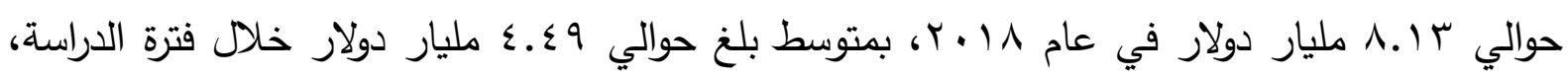

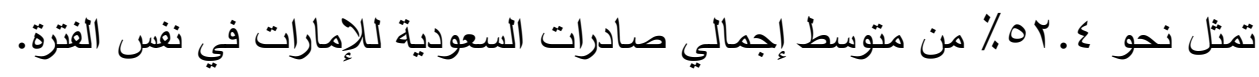

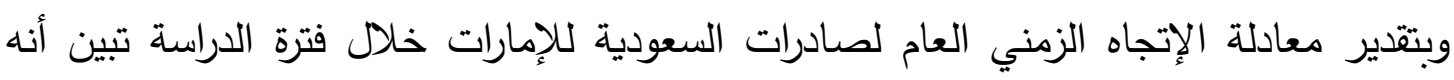

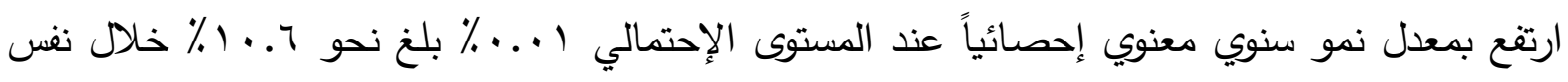

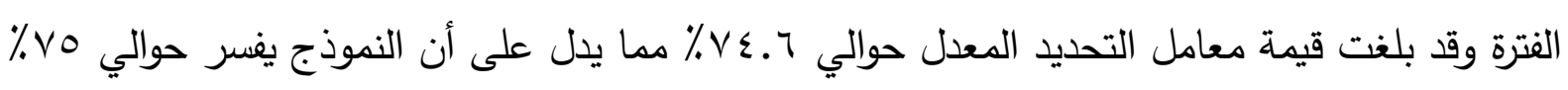
من التغيرات التي تحدث لصادرات السعودية للإمارات كما يتضح من المعادلة التالية: $\operatorname{Ln} \hat{Y}_{\mathbf{i}}=14.08+0.106 T_{i}$

$(\mathbf{8 5 . 5 3}) * * \quad(7.34)^{* * *}$

$$
\mathbf{F}=(\mathbf{5 3 . 8 6}) * * \quad \mathbf{R}^{-2}=\mathbf{0 . 7 4 6}
$$

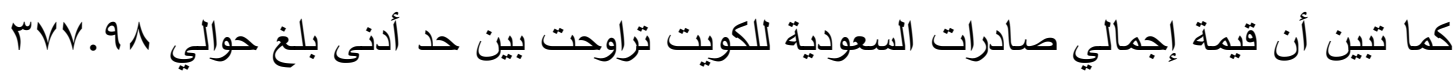

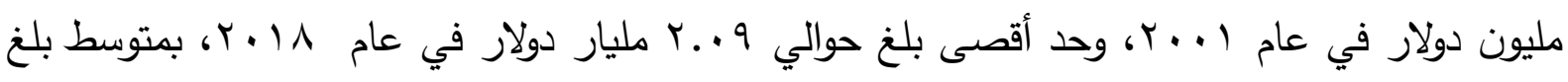

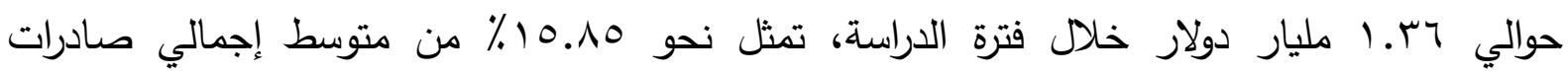
السعودية للكويت في نفس الفترة.

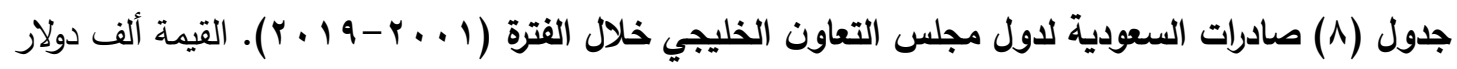




\begin{tabular}{|c|c|c|c|c|c|c|}
\hline جملة الصـادرات & عمان & قطر & البحرين & الكويت & الإمار ات & السنو ات \\
\hline 1657815 & 134045 & 170833 & 117003 & 377980 & 857954 & 2001 \\
\hline 2064993 & 172024 & 226251 & 280509 & 500980 & 885229 & 2002 \\
\hline 3344092 & 259130 & 335791 & 426608 & 746727 & 1575836 & 2003 \\
\hline 4217461 & 236449 & 477505 & 504263 & 1029670 & 1969574 & 2004 \\
\hline 5089155 & 351927 & 663911 & 683780 & 1125644 & 2263893 & 2005 \\
\hline 6776696 & 373357 & 978323 & 918156 & 1246751 & 3260109 & 2006 \\
\hline 8907526 & 443093 & 1402493 & 1152368 & 1477373 & 4432199 & 2007 \\
\hline 9672164 & 655017 & 1549853 & 1428018 & 1453584 & 4585692 & 2008 \\
\hline 9600840 & 549979 & 1804581 & 1303199 & 1271482 & 4671599 & 2009 \\
\hline 8414526 & 574076 & 1400747 & 1218997 & 1340628 & 3880078 & 2010 \\
\hline 10054234 & 772012 & 1364886 & 1233372 & 1543052 & 5140912 & 2011 \\
\hline 10828324 & 882193 & 1393093 & 1445106 & 1578475 & 5529457 & 2012 \\
\hline 11883250 & 895663 & 1474441 & 1536652 & 1590387 & 6386107 & 2013 \\
\hline 11806145 & 900806 & 1511711 & 1582351 & 1502417 & 6308860 & 2014 \\
\hline 12385773 & 881441 & 1622543 & 1534360 & 1573981 & 6773448 & 2015 \\
\hline 12331257 & 797977 & 1657750 & 1550426 & 1758280 & 6566824 & 2016 \\
\hline 12803288 & 960889 & 620382 & 1576060 & 1959126 & 7686831 & 2017 \\
\hline 13120387 & 1062835 & 45 & 1839745 & 2085817 & 8131945 & 2018 \\
\hline 7711384 & 827670 & 1 & 883169 & 1623893 & 4376651 & 2019 \\
\hline 8561542.6 & "617399.1 & "981849.5 & 1116533.8 & 1357170.9 & 44488589.4 & متوسط \\
\hline
\end{tabular}

المصدر: Trade statistics for international business development Trade map

وبتقدير معادلة الإتجاه الزمني العام لصادرات السعودية للكويت خلال فترة الدراسة تبين أنه ارتفع

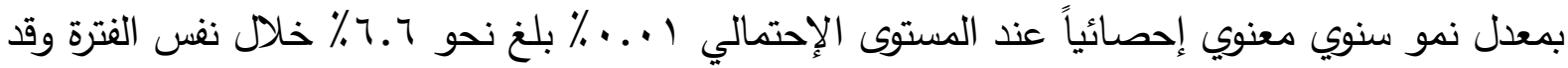

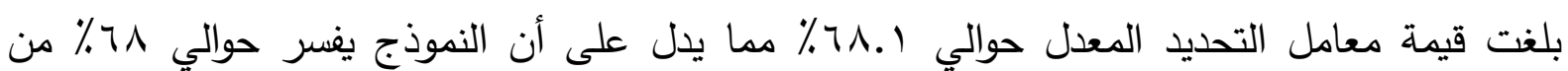
التغيرات التي تحدث لصادرات السعودية للكويت كما يتضح من المعادلة التالية:

$$
\begin{array}{cc}
\operatorname{Ln} \hat{Y}_{\mathbf{i}}=14.08+0.106 \mathbf{T}_{\mathbf{i}} \\
(85.53)^{* *} & (7.34)^{* *} \\
\mathbf{F}=(39.49) * * & \mathbf{R}^{-2}=0.681
\end{array}
$$

وقد اتضح أن قيمة إجمالي صادرات السعودية للبحرين تراوحت بين حد أدنى بلغ حوالي 117

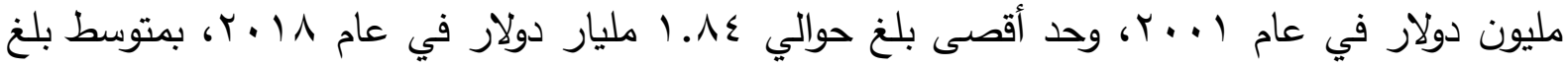

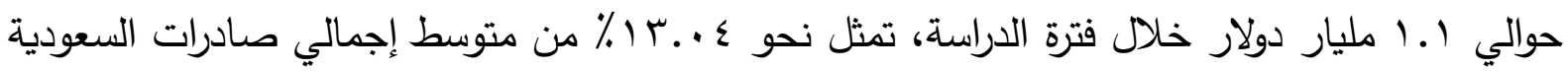
للبحرين في نفس الفترة. وبتقدير معادلة الإتجاه الزمني العام لصادرات السعودية للبحرين خلال فترة الدراسة تبين أنه ارتفع بمعدل نمو سنوي معنوي إحصائياً عند المستوى الإحتمالي ا ... ٪ بلغ نحو ج. . 1 خلال نفس 


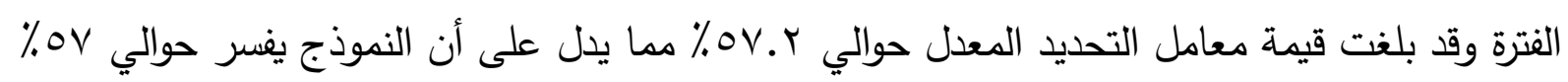
من التغيرات التي تحدث لصادرات السعودية للبحرين كما يتضح من المعادلة التالية:

$$
\begin{array}{cc}
\operatorname{Ln} \hat{\mathbf{Y}}_{\mathbf{i}}=\mathbf{1 2 . 7 7 + 0 . 0 9 9} \mathrm{T}_{\mathbf{i}} \\
(\mathbf{5 6 . 8 8})^{* *} & (\mathbf{5 . 0 0}) * * \\
\mathbf{F}=(\mathbf{2 5 . 0 6}) * * & \mathbf{R}^{-2}=\mathbf{0 . 5 7 2}
\end{array}
$$

وتبين أن قيمة إجمالي صادرات السعودية لقطر تراوحت بين حد أدنى بلغ حوالي ألف دولار فقط

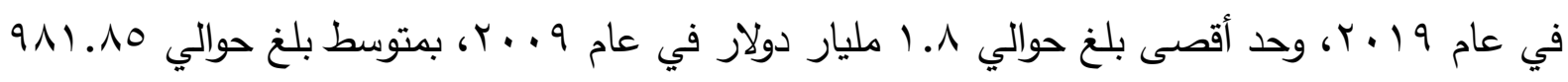

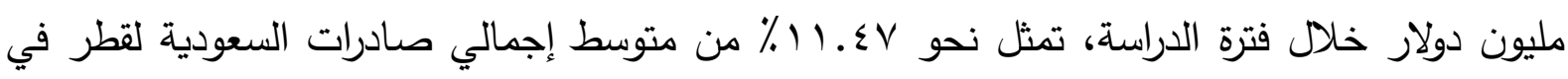

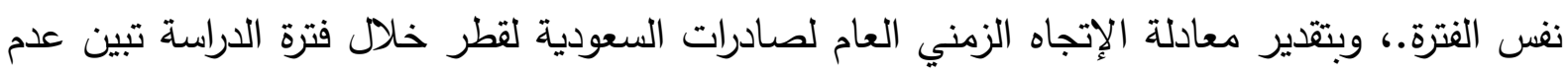
معنوية هذا المتغير

واتضح أن قيمة إجمالي صادرات السعودية لعمان تراوحت بين حد أدنى بلغ حوالي 134 مليون

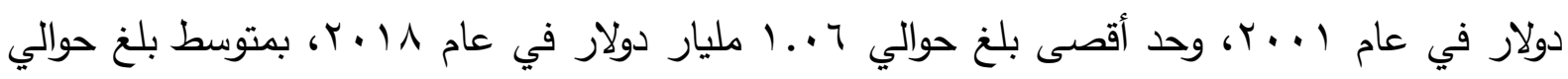

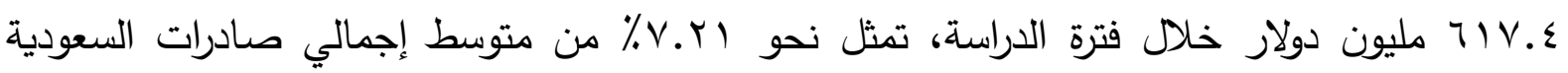
لعمان في نفس الفترة. وبتقدير معادلة الإتجاه الزمني العام لصادرات السعودية لعمان خلال فترة الدراسة تبين أنه ارتفع

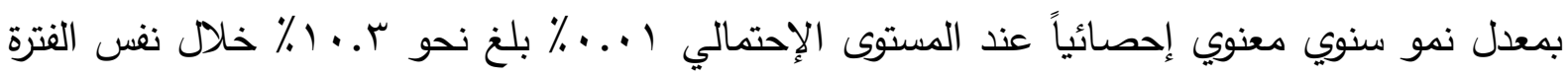

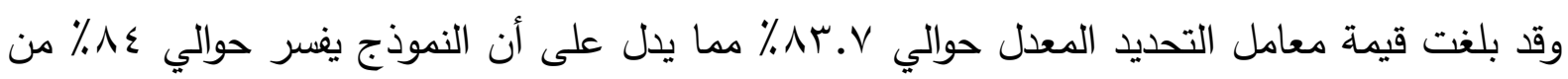
التغيرات التي تحدث لصادرات السعودية لعمان كما يتضح من المعادلة التالية:

$$
\operatorname{Ln} \hat{\mathbf{Y}}_{\mathbf{i}}=\mathbf{1 2 . 1 5}+\mathbf{0 . 1 0 3} \mathrm{T}_{\mathbf{i}}
$$

$$
\begin{array}{cc}
(100.3) * * & (9.67) * * \\
\mathbf{F}=(\mathbf{9 3 . 5 6}) * * & \mathbf{R}^{-2}=0.837
\end{array}
$$

ومما سبق يتضح أن صادرات السعودية لدول مجلس التعاون تتركز في دولة الإمارات بنسبة تقدر بنحو

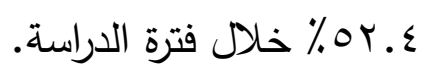

ب) واردات السعودية من دول مجلس التعاون الخليجي خلال فترة الاراسة:

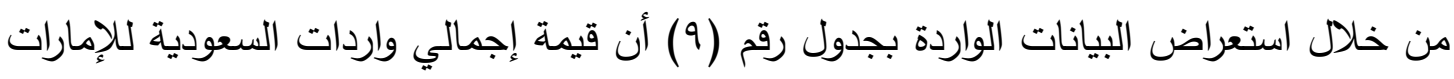

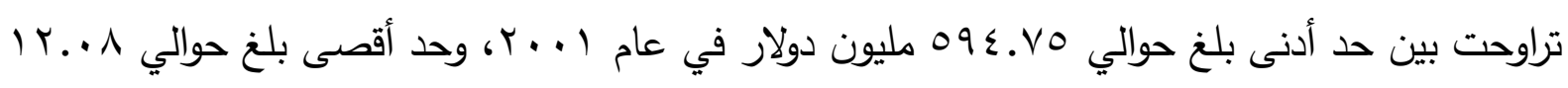

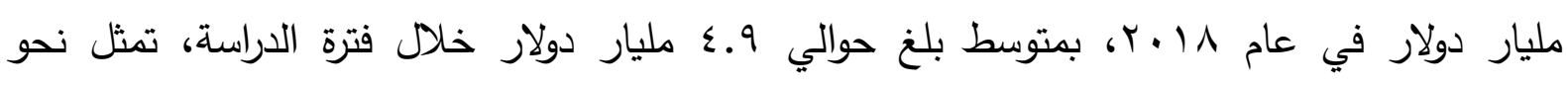

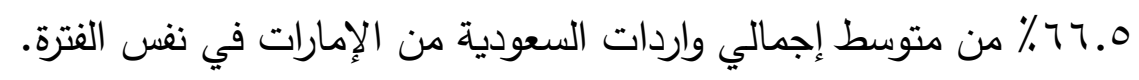


وبتقدير معادلة الإتجاه الزمني العام لواردات السعودية من الإمارات خلال فترة الدراسة تبين أنه

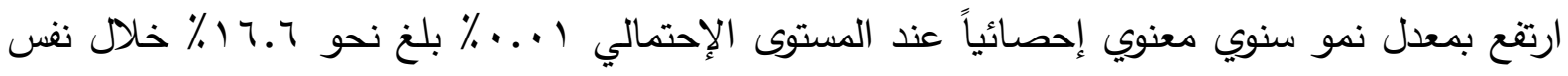

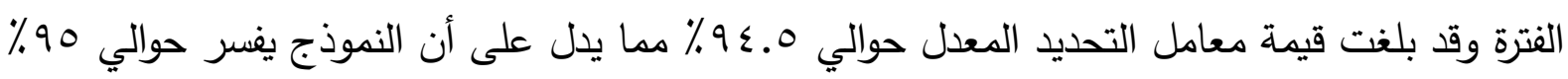
من التغيرات التي تحدث لواردات السعودية من الإمارات كما يتضح من المعادلة التالية: $\mathbf{L n} \hat{\mathbf{Y}}_{\mathbf{i}}=13.38+0.166 \mathrm{~T}_{\mathbf{i}}$

$$
\begin{array}{cc}
(124.3) * * & (17.59) * * \\
\mathbf{F}=(309.5) * * & \mathbf{R}^{-2}=\mathbf{0 . 9 4 5}
\end{array}
$$

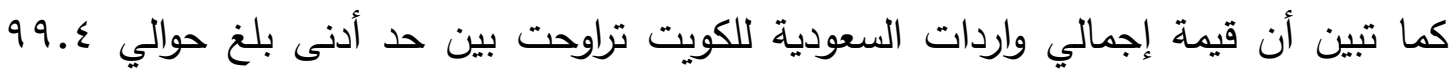

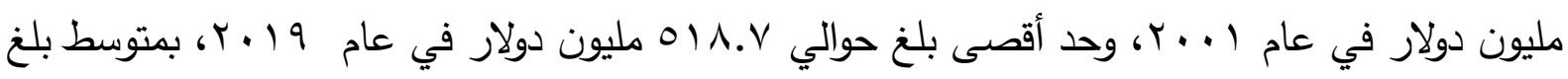

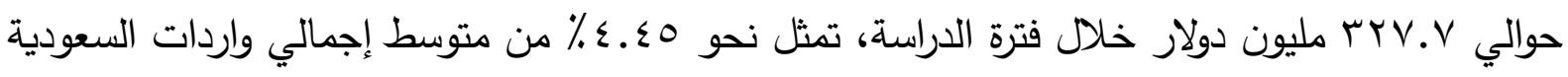
من الكويت في نفس الفترة.

\begin{tabular}{|c|c|c|c|c|c|c|}
\hline جملة الو ارددات & عمان & قطر & البحرين & الكويت & الإمار ات & السنوات \\
\hline 1147477 & 128437 & 133387 & 191464 & 99436 & 594753 & 2001 \\
\hline 1413301 & 111540 & 142980 & 267126 & 114360 & 777295 & 2002 \\
\hline 1618865 & 146134 & 167264 & 257708 & 122808 & 924951 & 2003 \\
\hline 2200229 & 153288 & 186162 & 494811 & 207614 & 1158354 & 2004 \\
\hline 2637657 & 235017 & 125237 & 564029 & 210672 & 1502702 & 2005 \\
\hline 3190060 & 224230 & 210127 & 681351 & 212401 & 1861951 & 2006 \\
\hline 3768422 & 286884 & 250702 & 822296 & 210694 & 2197846 & 2007 \\
\hline 4877578 & 463809 & 124532 & 1171753 & 297225 & 2820259 & 2008 \\
\hline 4596187 & 381212 & 174994 & 932339 & 280088 & 2827554 & 2009 \\
\hline 5867693 & 462517 & 247225 & 1068087 & 358950 & 3730914 & 2010 \\
\hline 8474518 & 897767 & 475601 & 1264504 & 442965 & 5393681 & 2011 \\
\hline 10231987 & 1458021 & 601195 & 1321916 & 401048 & 6449807 & 2012 \\
\hline 12825679 & 1562126 & 633442 & 1685368 & 487570 & 8457173 & 2013 \\
\hline 12644536 & 1442755 & 558763 & 1926747 & 511894 & 8204377 & 2014 \\
\hline 12667939 & 1169174 & 468499 & 1926354 & 477040 & 8626872 & 2015 \\
\hline 10036363 & 1015681 & 318817 & 1345550 & 426600 & 6929715 & 2016 \\
\hline 11430585 & 1299394 & 178555 & 1307668 & 429266 & 8215702 & 2017 \\
\hline 15832707 & 1779601 & 3 & 1555360 & 417458 & 12080285 & 2018 \\
\hline 14478970 & 1883991 & 8 & 1711676 & 518706 & 10364589 & 2019 \\
\hline 7365302.8 & 794819.9 & 263025.9 & 1078742.5 & 327726.1 & 4900988.4 & متوسط \\
\hline
\end{tabular}

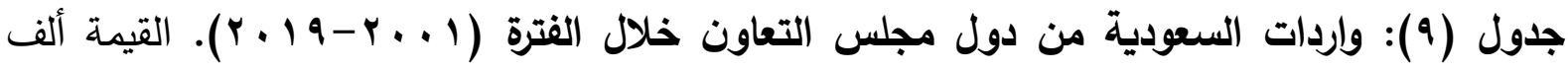

المصدر: Trade statistics for international business development Trade map

وبتقدير معادلة الإتجاه الزمني العام لواردات السعودية من الكويت خلال فترة الدراسة تبين أنه

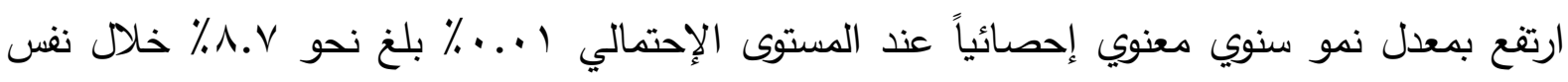




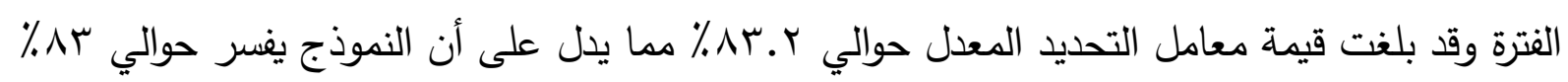
من التغيرات التي تحدث لواردات السعودية من الكويت كما يتضح من من المعادلة التالية: $\operatorname{Ln} \hat{\mathbf{Y}}_{\mathbf{i}}=11.72+0.087 \mathrm{~T}_{\mathbf{i}}$

$$
\begin{array}{cl}
(112.3) * * & (9.49) * * \\
\mathbf{F}=(\mathbf{8 9 . 9 6 )} * * & \mathbf{R}^{-2}=0.681
\end{array}
$$

وقد اتضح أن قيمة إجمالي واردات السعودية من البحرين تراوحت بين حد أدنى بلغ حوالي

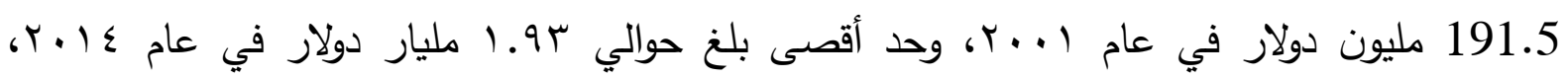

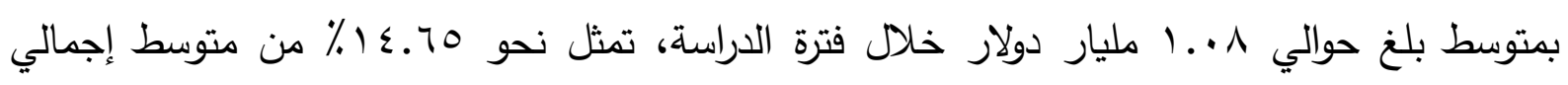
واردات السعودية من البحرين في نفس الفترة. وبتقدير معادلة الإتجاه الزمني العام واردات السعودية من البحرين خلال فترة الدراسة تبين أنه

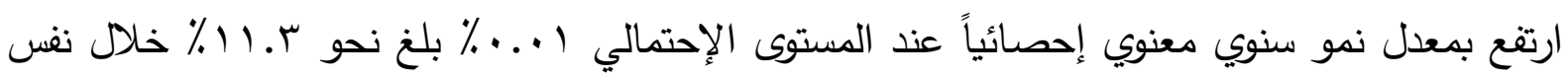

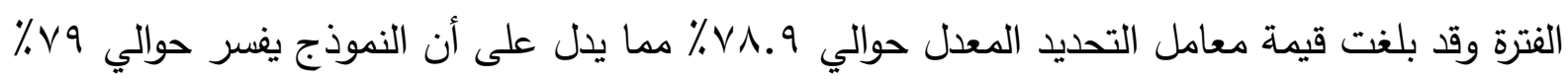
من التغيرات التي تحدث لواردات السعودية من البحرين كما يتضح من المعاديد ملادلة التالية:

$$
\begin{array}{cc}
\operatorname{Ln} \hat{Y}_{i}=12.58+0.113 T_{i} \\
(80.96)^{* *} & (8.26)^{* *} \\
F=(68.28) * * & R^{-2}=0.789
\end{array}
$$

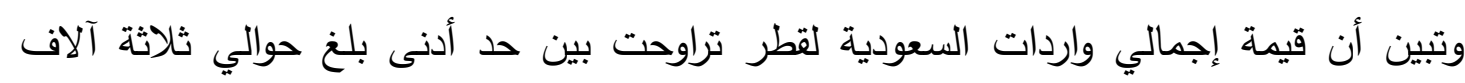

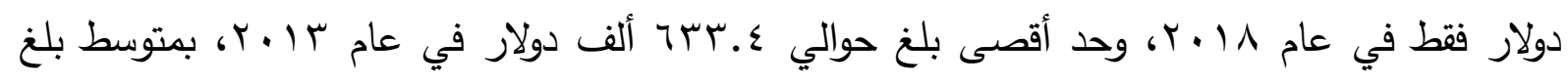

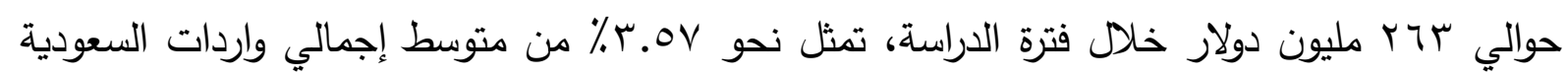

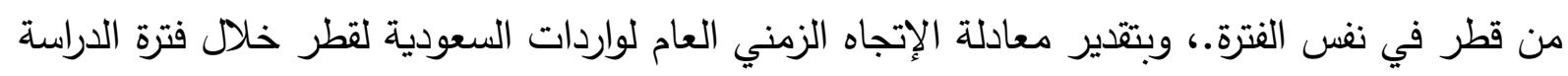
تبين عدم معنوية هذا المتغير فئري

واتضح أن قيمة إجمالي واردات السعودية من عمان تراوحت بين حد أدنى بلغ حوالي 111.5

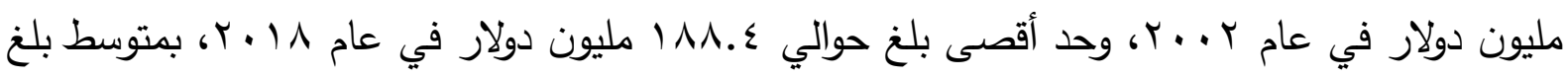

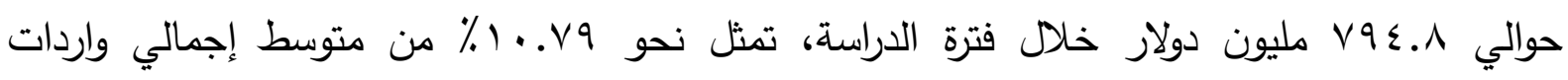
السعودية من عمان في نفس الفترة. وبتقدير معادلة الإتجاه الزمني العام لواردات السعودية من عمان خلال فترة الدراسة تبين أنه

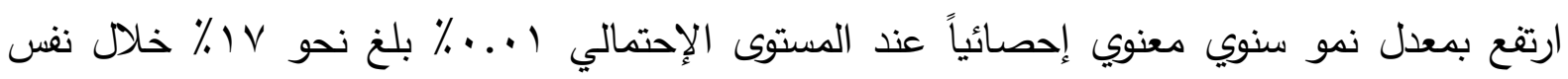

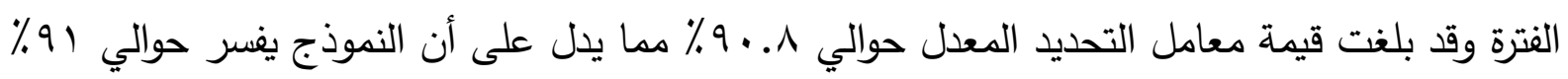
من التغيرات التي تحدث لواردات السعودية من عمان كما يتضح من المعادلة التالية:

$$
\operatorname{Ln} \hat{Y}_{\mathbf{i}}=11.487+0.170 T_{i}
$$




$$
\mathbf{F}=(\mathbf{1 7 7 . 9 4 )})^{(79.24) * *} \quad \begin{gathered}
(13.34) * * * \\
\mathbf{R}^{-2}=\mathbf{0 . 9 0 8}
\end{gathered}
$$

ومما سبق يتضح أن واردات السعودية من دول مجلس التعاون تتركز في دولة الإمارات بنسبة تقدر بنحو

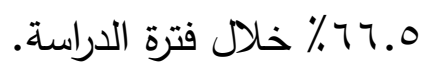

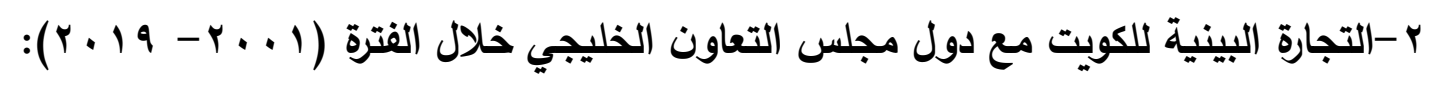
أ) صادرات الكويت لدول مجلس التعاون الخليجي خلال فترة الاراسة:

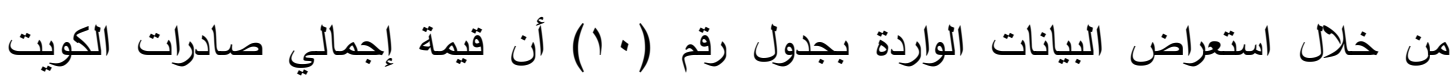

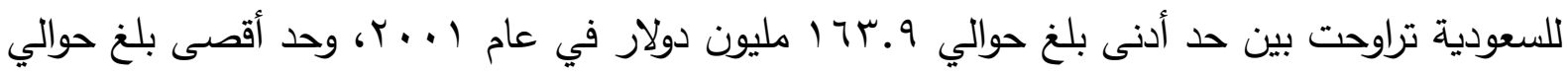

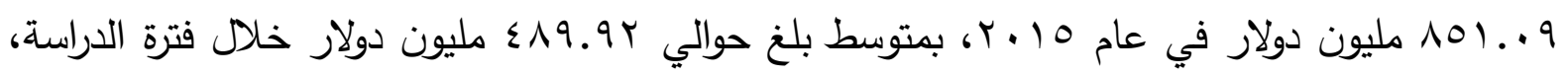

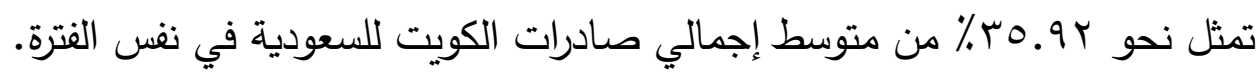

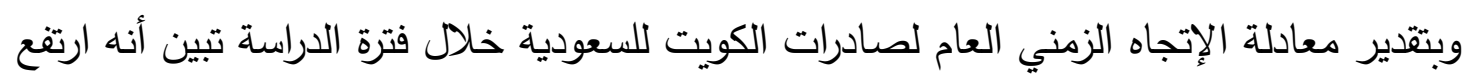

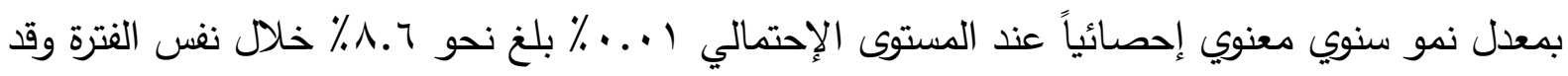

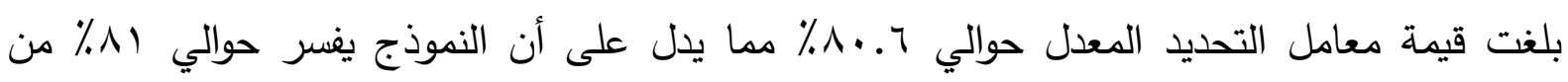
التغيرات التي تحدث لصادرات الكويت للسعودية كما يتضح من المعادلة التالية:

$$
\operatorname{Ln} \hat{\mathbf{Y}}_{\mathbf{i}}=12.12+0.086 \mathrm{~T}_{\mathrm{i}}
$$

$$
\begin{array}{cc}
\begin{array}{c}
(107.1) * * \\
\mathbf{F}=(\mathbf{7 5 . 7 3}) * *
\end{array} & (\mathbf{8 . 7 0}) * * \\
\mathbf{R}^{-2}=\mathbf{0 . 8 0 6}
\end{array}
$$

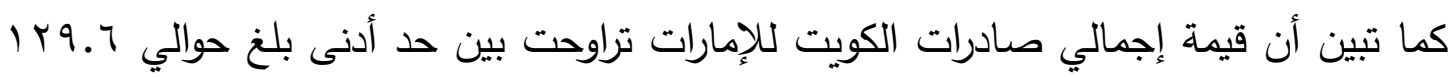

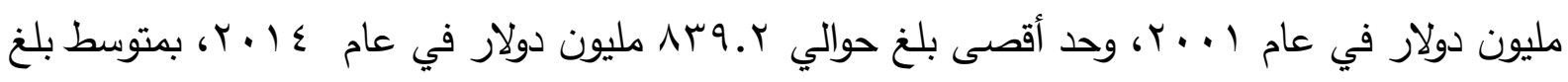

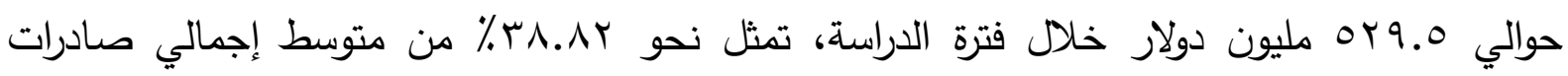
الكويت للإمارات في نفس الفترة. وبتقدير معادلة الإتجاه الزمني العام لصادرات الكويت للإمارات خلال فترة الدراسة تبين أنه ارتفع

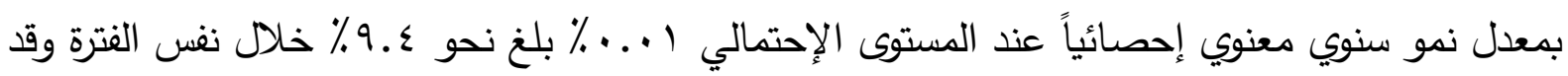

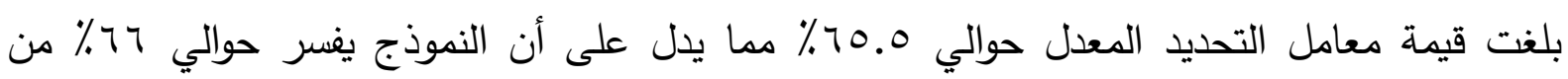
التغيرات التي تحدث لصادرات الكويت للإمارات كما يتضح من المعادلة التالية:

$$
\operatorname{Ln} \hat{\mathbf{Y}}_{\mathbf{i}}=12.09+0.094 \mathrm{~T}_{\mathbf{i}}
$$

$$
\begin{aligned}
& (67.17)^{* *} \quad(5.93)^{* * *} \\
& \mathbf{F}=(\mathbf{3 5 . 1 4}) * * \quad \mathbf{R}^{-2}=\mathbf{0 . 6 5 5}
\end{aligned}
$$

وقد اتضح أن قيمة إجمالي صادرات الكويت للبحرين تراوحت بين حد أدنى بلغ حوالي 25.2

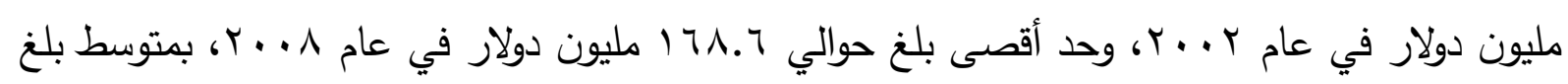




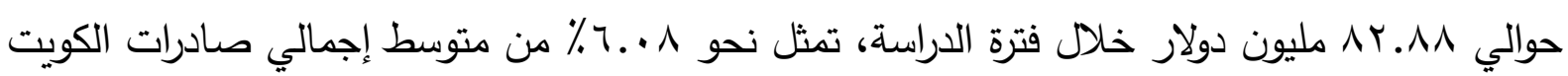
للبحرين في نفس الفترة.

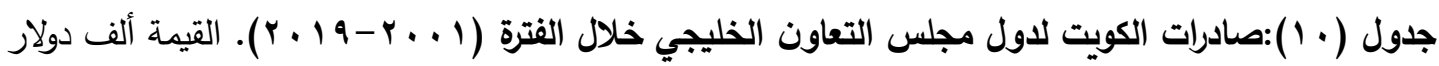

\begin{tabular}{|c|c|c|c|c|c|c|}
\hline جملة الصـادر ات & عمان & قطر & البحرين & الإمار ات & السعودية & السنو ات \\
\hline 364494 & 22362 & 22628 & 25982 & 129632 & 163890 & 2001 \\
\hline 393806 & 21523 & 36595 & 25212 & 137905 & 172571 & 2002 \\
\hline 488889 & 18524 & 32366 & 41902 & 166870 & 229227 & 2003 \\
\hline 489313 & 21012 & 33802 & 35731 & 191596 & 207172 & 2004 \\
\hline 684695.5 & 23159 & 81447 & 45012 & 268058 & 267021 & 2005 \\
\hline 880078 & 25305 & 129091 & 54293 & 344520 & 326869 & 2006 \\
\hline 1188872 & 44874 & 198372 & 88875 & 523183 & 333568 & 2007 \\
\hline 1553622 & 59783 & 208405 & 168603 & 691193 & 425638 & 2008 \\
\hline 1382331 & 65652 & 147036 & 143408 & 585164 & 441071 & 2009 \\
\hline 1410614 & 83994 & 125890 & 103596 & 606983 & 490151 & 2010 \\
\hline 1682823 & 82770 & 142558 & 82962 & 686083 & 688450 & 2011 \\
\hline 1907017 & 188938 & 168220 & 112954 & 731615 & 705290 & 2012 \\
\hline 1916532 & 128698 & 161413 & 96114 & 834735 & 695572 & 2013 \\
\hline 1988283 & 107845 & 197875 & 97527 & 839234 & 745802 & 2014 \\
\hline 2114189 & 87528 & 238773 & 118202 & 818592 & 851094 & 2015 \\
\hline 1674312 & 144907 & 175286 & 105544 & 548306 & 700269 & 2016 \\
\hline 1885993 & 194638 & 358143 & 86166 & 589499 & 657547 & 2017 \\
\hline 2052149 & 200880 & 428822 & 75856 & 797857 & 548734 & 2018 \\
\hline 1858961 & 204234 & 359563 & 66838 & 569836 & 658490 & 2019 \\
\hline 1364051.2 & 90875.0 & 170857.1 & 82883.0 & 529519.0 & 489917.1 & متوسط \\
\hline
\end{tabular}

المصدر: Trade statistics for international business development Trade map

وبتقدير معادلة الإتجاه الزمني العام لصادرات الكويت للبحرين خلال فترة الدراسة تبين أنه ارتفع

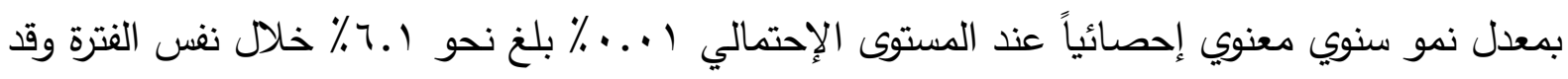
بلغت قيمة معامل التحديد المعدل حوالي 9.0 التغيرات التي تحدث لصادرات الكويت للبحرين كما يتضح من المعادلة التالية: $\operatorname{Ln} \hat{\mathbf{Y}}_{\mathbf{i}}=10.59+0.061 \mathrm{~T}_{\mathbf{i}}$

$\mathbf{F}=\left(\begin{array}{rr}(\mathbf{1 1 0 . 4 1}) * * & (3.33) * * \\ (1 * & \mathbf{R}^{-2}=\mathbf{0 . 3 5 9}\end{array}\right.$

وتبين أن قيمة إجمالي صادرات الكويت لقطر تراوحت بين حد أدنى بلغ حوالي ج. ج مليون

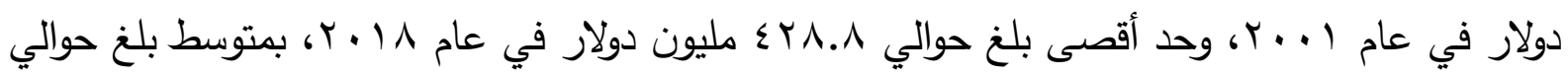

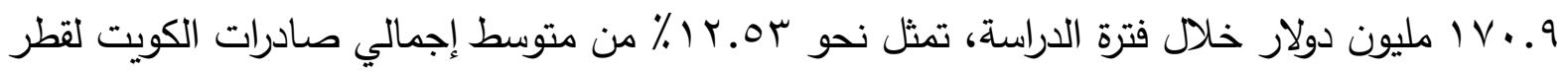
في نفس الفترة.، وبتقدير معادلة الإتجاه الزمني العام لصادرات الكويت لقطر خلال فترة الدراسة تبين أنه 


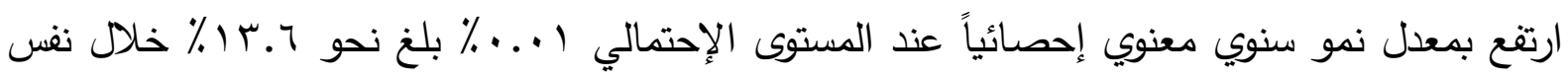

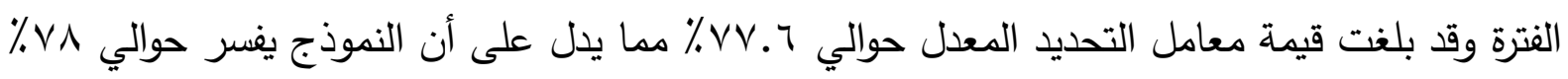
من التغيرات التي تحدث لصادرات الكويت لقطر كما يتضح من المعادلة التالية: $\operatorname{Ln} \hat{Y}_{\mathbf{i}}=10.41+0.136 T_{i}$

$$
\mathbf{F}=\left(\begin{array}{cr}
(\mathbf{6 3 . 4 3}) * * & (\mathbf{7 . 9 6})^{* *} \\
\mathbf{R}^{-2}=\mathbf{0 . 7 7 6}
\end{array}\right.
$$

واتضح أن قيمة إجمالي صادرات الكويت لعمان تراوحت بين حد أدنى بلغ حوالي 18.5 مليون

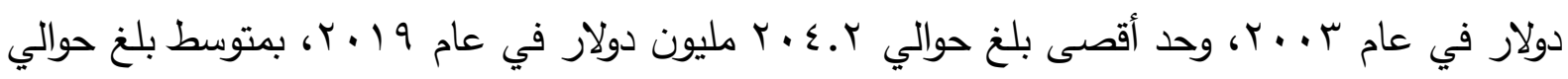

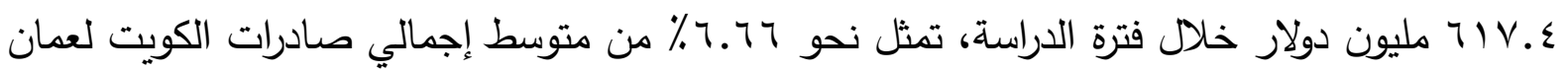
في نفس الفترة. وبتقدير معادلة الإتجاه الزمني العام لصادرات الكويت لعمان خلال فترة الدراسة تبين أنه ارتفع

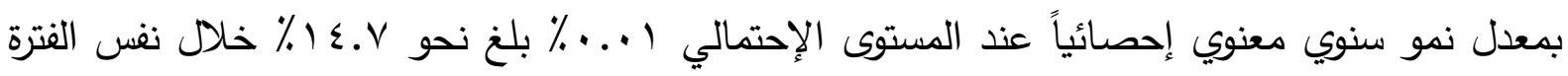

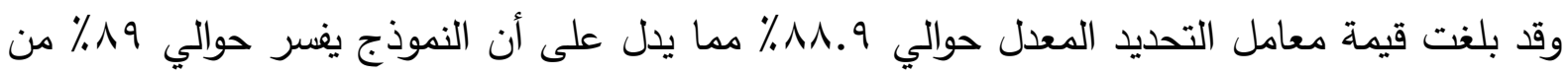
التغيرات التي تحدث لصادرات الكويت لعمان كما يتضح من المعادلة التالية:

$$
\begin{gathered}
\operatorname{Ln} \hat{Y}_{i}=9.62+0.147 T_{i} \\
(69.18)^{* * *} \quad(12.08)
\end{gathered}
$$$$
\mathbf{F}=(\mathbf{1 4 5 . 8 )}) * *
$$

$$
\mathbf{R}^{-2}=\mathbf{0 . 8 8 9}
$$

ومما سبق يتضح أن صادرات الكويت لدول مجلس التعاون تتركز في دولة الإمارات بنسبة تقدر بنحو

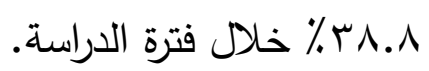

ب) واردات الكويت من دول مجلس التعاون الخليجي خلال فترة الاراسة:

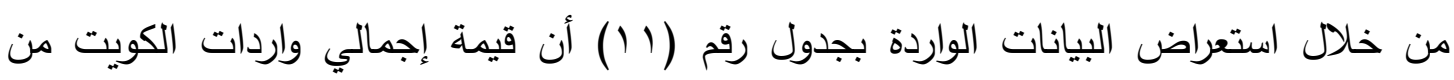

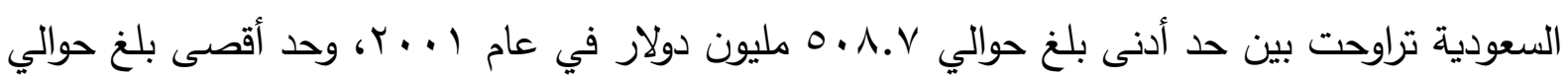

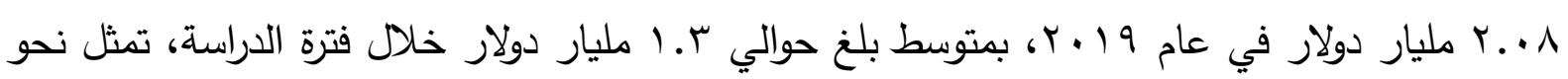

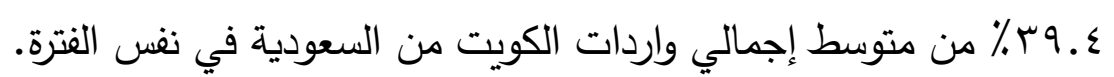

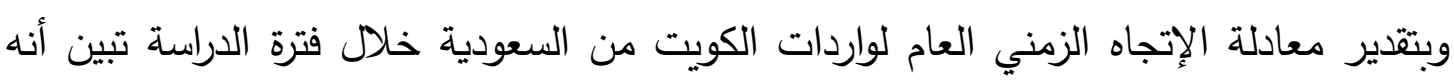

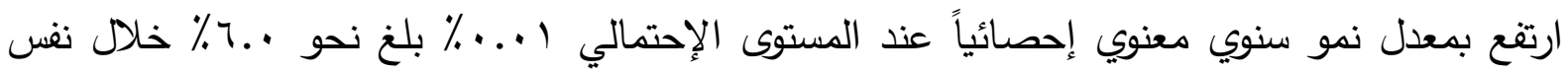

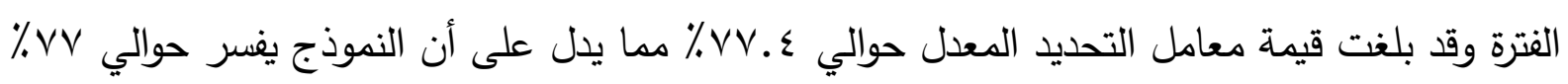
من التغيرات التي تحدث لواردات الكويت من السعودية كما يتضح من المعادلة التالية:

$$
\begin{array}{cc}
\operatorname{Ln} \hat{Y}_{\mathbf{i}}=13.45+0.060 \mathrm{~T}_{\mathbf{i}} \\
\quad(\mathbf{1 5 6 . 4}) * * & (\mathbf{7 . 9 2})^{* *} \\
\mathrm{~F}=(\mathbf{6 2 . 6 5}) * * & \mathbf{R}^{-2}=\mathbf{0 . 7 7 4}
\end{array}
$$




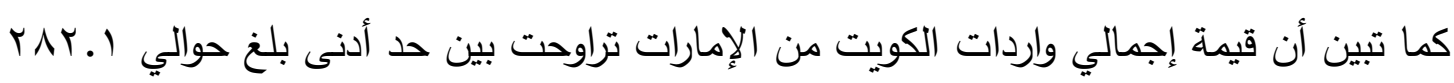

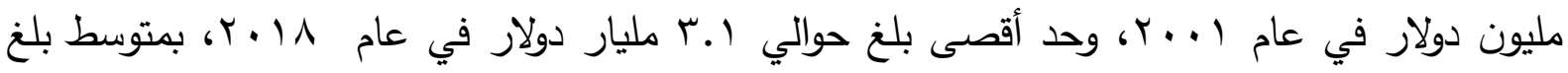

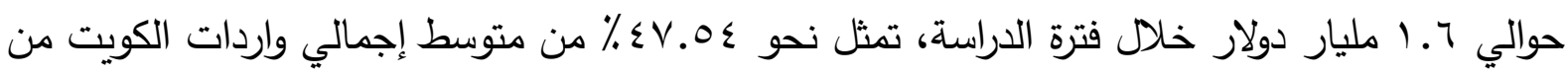
الإمارات في نفس الفترة.

جدول (11): واردات الكويت من دول مجلس التعاون خلال الفترة (1 . . Y -9 1 ـ ب). القيمة ألف دولار

\begin{tabular}{|c|c|c|c|c|c|c|}
\hline جملة الواردات & عمان & قطر & البحرين & الإمارات & السعودية & السنو ات \\
\hline 878248 & 25517 & 15147 & 46775 & 282110 & 508699 & 2001 \\
\hline 989169 & 28051 & 15939 & 46498 & 317474 & 581207 & 2002 \\
\hline 1258513 & 40200 & 11990 & 51879 & 408690 & 745754 & 2003 \\
\hline 1685515 & 46339 & 12167 & 59358 & 567106 & 1000545 & 2004 \\
\hline 2077047 & 59222 & 13392 & 85322 & 734360 & 1184753 & 2005 \\
\hline 2468579 & 72104 & 14617 & 111285 & 901613 & 1368960 & 2006 \\
\hline 2285342 & 89753 & 31280 & 89961 & 786074 & 1288274 & 2007 \\
\hline 2663651 & 101028 & 50219 & 136843 & 982276 & 1393285 & 2008 \\
\hline 2281376 & 74620 & 33041 & 100386 & 868166 & 1205163 & 2009 \\
\hline 2528495 & 90619 & 89781 & 135139 & 1010668 & 1202288 & 2010 \\
\hline 3655784 & 304075 & 163152 & 143399 & 1602826 & 1442332 & 2011 \\
\hline 3942236 & 226178 & 154278 & 147191 & 1979933 & 1434656 & 2012 \\
\hline 4786969 & 502586 & 130389 & 175550 & 2573552 & 1404892 & 2013 \\
\hline 5400510 & 494609 & 113673 & 269219 & 2952717 & 1570292 & 2014 \\
\hline 5321751 & 243009 & 104247 & 416438 & 2976211 & 1581846 & 2015 \\
\hline 4943219 & 213632 & 93443 & 306567 & 2807709 & 1521868 & 2016 \\
\hline 5346156 & 226587 & 51856 & 303475 & 2928613 & 1835625 & 2017 \\
\hline 6224547 & 261427 & 50819 & 770210 & 3099987 & 2042104 & 2018 \\
\hline 5634468 & 214158 & 61216 & 462199 & 2821390 & 2075505 & 2019 \\
\hline 3387977.6 & 174406.0 & 63718.2 & 203036.5 & 1610603.9 & 1336213.0 & متوسط \\
\hline
\end{tabular}

المصدر: Trade statistics for international business development Trade map

وبتقدير معادلة الإتجاه الزمني العام لواردات الكويت من الإمارات خلال فترة الدراسة تبين أنه

ارتفع بمعدل نمو سنوي معنوي إحصائياً عند المستوى الإحتمالي ا... ٪ بلغ نحو ؛ ( خلال نفس

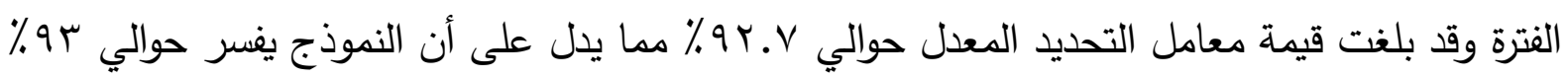
من التغيرات التي تحدث لواردات الكويت من الإمارات كما يتضح من المعادلة التالية: $\operatorname{Ln} \hat{Y}_{i}=12.62+0.140 T_{i}$

$\begin{aligned}(119.9) * * & (15.14) * * \\ \mathbf{F}=(229.2) * * & \mathbf{R}^{-2}=0.927\end{aligned}$


وقد اتضح أن قيمة إجمالي واردات الكويت من البحرين تراوحت بين حد أدنى بلغ حوالي 46.5

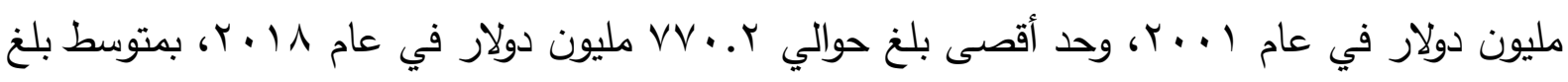
حوالي r.r مليون دولار خلال فترة الدراسة، تمثل نحو 0.99٪ من متوسط إجمالي واردات الكويت من البحرين في نفس الفترة.

وبتقدير معادلة الإتجاه الزمني العام واردات الكويت من البحرين خلال فترة الدراسة تبين أنه ارتفع بمعدل نمو سنوي معنوي إحصائياً عند المستوى الإحتمالي ا... ٪ بلغ نحو 9.ب ٪ خلال نفس

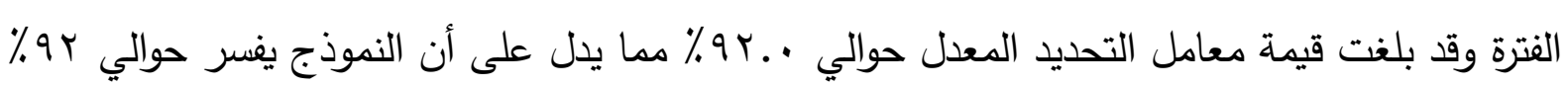
من التغيرات التي تحدث لواردات الكويت من البحرين كما يتضح من المعادلة التالية:

$$
\begin{array}{cc}
\operatorname{Ln} \hat{\mathbf{Y}}_{\mathbf{i}}=10.51+0.139 \mathrm{~T}_{\mathbf{i}} \\
(\mathbf{9 5 . 7 0}) * * & (\mathbf{1 4 . 4 4}) * * \\
\mathbf{F}=(\mathbf{2 0 8 . 6}) * * & \mathbf{R}^{-2}=\mathbf{0 . 9 2 0}
\end{array}
$$

وتبين أن قيمة إجمالي واردات الكويت من قطر تراوحت بين حد أدنى بلغ حوالي 99 .11 ألف

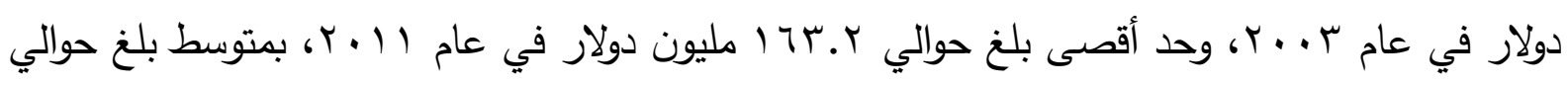

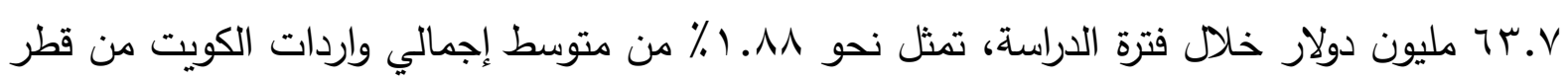
في نفس الفترة.، وبتقدير معادلة الإتجاه الزمني العام لواردات الكويت من قطر خلال فترة الدراسة تبين أنه ارتفع بمعدل نمو سنوي معنوي إحصائياً عند المستوى الإحتمالي ا...٪ بلغ نحو \&.ب ٪ خلال نفس الفترة وقد بلغت قيمة معامل التحديد المعدل حوالي ؟.به\% مما يدل على أن النموذج يفسر حوالي ؛ه \% من التغيرات التي تحدث لواردات الكويت من قطر كما يتضح من المعادلة التالية:

$$
\begin{aligned}
& \operatorname{Ln} \hat{\mathbf{Y}}_{\mathbf{i}}=9.54+0.124 \mathrm{~T}_{\mathrm{i}} \\
& (31.11) * * \quad(4.67) * * \\
& \mathbf{F}=\left(\mathbf{2 1 . 7 9 )} * * \quad \mathbf{R}^{-2}=\mathbf{0 . 5 3 6}\right.
\end{aligned}
$$


واتضح أن قيمة إجمالي واردات الكويت من عمان تراوحت بين حد أدنى بلغ حوالي 25.5

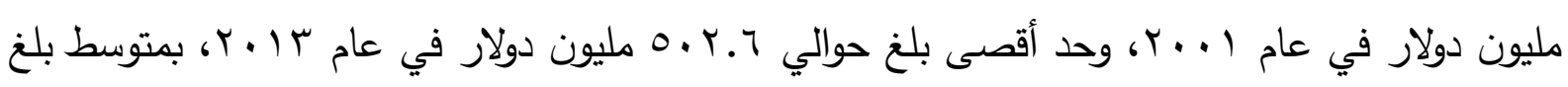
حوالي ع. ع ا مليون دولار خلال فترة الدراسة، تمثل نحو 10 ـ0\% من متوسط إجمالي واردات الكويت من عمان في نفس الفترة. وبتقدير معادلة الإتجاه الزمني العام لواردات الكويت من عمان خلال فترة الدراسة تبين أنه ارتفع

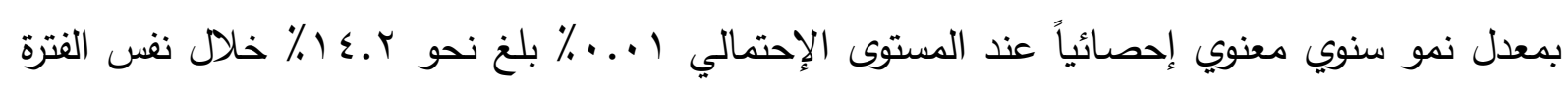

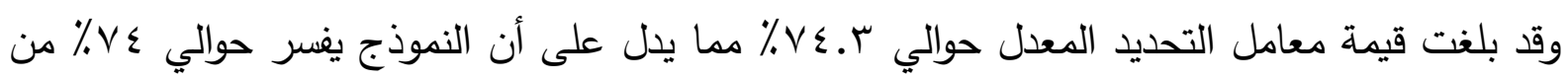
التغيرات التي تحدث لواردات الكويت من عمان كما يتضح من المعادلة التالية:

$$
\operatorname{Ln} \hat{\mathbf{Y}}_{\mathrm{i}}=\mathbf{1 0 . 2 8}+0.142 \mathrm{~T}_{\mathrm{i}}
$$

$$
\begin{array}{rr}
(\mathbf{4 6 . 0 8})^{* *} & (\mathbf{7 . 2 8}) * * \\
\mathbf{F}=(\mathbf{5 3 . 0 3}) * * & \mathbf{R}^{-2}=\mathbf{0 . 7 4 3}
\end{array}
$$

ومما سبق يتضح أن واردات الكويت من دول مجلس التعاون تتركز في دولة الإمارات بنسبة تقدر بنحو

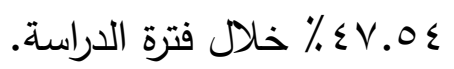




\section{الملخص}

حدث تحسن طفيف في نمو اقتصاد مجلس التعاون الخليجي في عامي 2018 م و 2019م نتيجة التزام دول مجلس التعاون بخفض الإنتاج ضمن اتفاق منظمة أوبك والمنتجين المستقلين لدعم أسعار النفط في الأسواق العالمية، وعليه سيعتمد نمو الاقتصاد في مجلس التعاون بشكل أساسي على القطاعات غير النفطية خلال الفترة القادمة.، وفي المقابل سيشكل إرتفاع أسعار الفائدة وزيادة تكاليف الاقتراض بالنسبة للمسهلكين والثركات، مع إنخفاض مستويات الإستهلالك والاستثمار والنشاط التجاري في إضافة المزيد من الضغوط على الأداء الاقتصادي •

واستهدف البحث التعرف على أثر الخدمات اللوجستية في دول مجلس التعاون الخليجى على

التجارة البينية لدول مجلس التعاون.، واعتمد البحث على اسلوب الاقتصاد الوصفي والقياسي من خلال استخدام تحليل الانحدار البسيط وتقدير معدلات النمو.، كما اعتمد البحث للحصوال على البيانات على المنظمة العالمية للتجارة، البنك الدولي، وبعض الدراسات والكتب ذات الصلة بموضوع البحث بالإضافة

شبكة المعلومات الدولية.

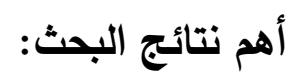

1- يتبين أن الميزان التجاري لدول مجلس التعاون الخليجي مجتمعة يحقق فائض خلال فترة الدراسة على الرغم من انخفاض نسبة تغطية الصادرات للواردات لدول مجلس التعاون، نتيجة نمو صادرات دول مجلس التعاون بمعدل أقل من معدل نمو واردت دول مجلس التعاون خلال نفس الفترة.

ץ- يحقق الميزان التجاري للسعودية فائض خلال فترة الدراسة على الرغم من انخفاض نسبة تغطية الصادرات للواردات لدول مجلس التعاون نظراً لزيادة صادراتها بمعدل نمو أقل من معدل 
نمو وارداتها خلال نفس الفترة. ، كما حقق الميزان التجاري للإمارات فائض خلال فترة الدراسة علماً بأن صادراتها تزداد بمعدل نمو يقترب كثيراً من معدل نمو وارداتها خلال نفس الفترة. ץ- حقق الميزان التجاري للكويت فائض خلال فترة الدراسة مع ملاحظة معدل نمو صادراتها يقترب كثيراً من معدل نمو وارداتها خلال نفس الفترة. ع- حقق الميزان التجاري للبحرين فائضاً في بعض السنوات، وحقق عجزاً في أغلب السنوات موضع الدراسة نتيجة انخفاض قيمة صادراتها عن قيمة وارداتها في تلك السنوات. ه- حقق الميزان التجاري لقطر فائض خلال فترة الدراسة مع ملاحظة معدل نمو صادراتها يفوق معدل نمو وارداتها خلال نفس الفترة. ؟- يحقق الميزان التجاري لسلطنة عمان فائض خلال فترة الدراسة مع ملاحظة معدل نمو صادراتها يفوق معدل نمو وارداتها خلال نفس الفترة. V - - ل يتضح أن صادرات وواردات السعودية من دول مجلس التعاون تتركز في دولة الإمارات بنسبة كبيرة خلال فترة الدراسة. 1- صادرات وواردات الكويت لدول مجلس التعاون تتركز في دولة الإمارات بنسبة خلال فترة الدراسة.

\section{المراجع}

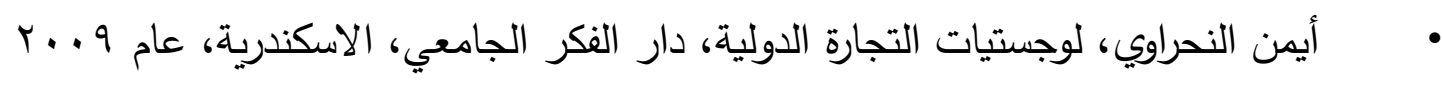
، ص VNז. عبد القادر فتحي لاثين ، المفاهيم الحديثة في إدارة خدمات النقل واللوجستيات، المنظمة العربية للتمية الإدارية، مصر ، الطبعة الثانية، عام 9 .. ب ، ص ^ץ. 


$$
\text { مجلة البحوث والدراسات الإفريقية ودول حوض النيل - جامعة أسون - المجلد (r) - العدد (r) - يناير ( r · r م) }
$$

• عبد المطلب عبد الحميد، الجات وآليات منظمة التجارة العالمية من أورجواي لسياتل

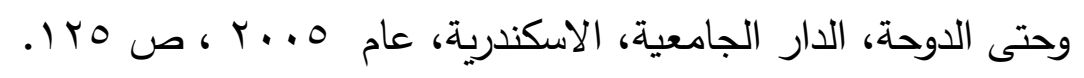

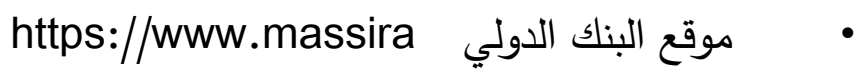

